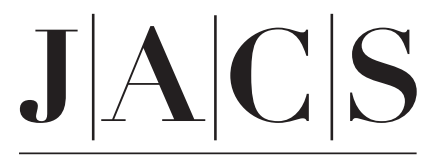

A R T I C L E S

Published on Web 09/07/2006

\title{
Ionic Core-Shell Dendrimers with an Octacationic Core as Noncovalent Supports for Homogeneous Catalysts
}

\author{
Rob van de Coevering, ${ }^{\dagger}$ Alfred P. Alfers, ${ }^{\dagger}$ Johannes D. Meeldijk, ${ }^{\ddagger}$ \\ Eloísa Martínez-Viviente, ,\$ Paul S. Pregosin, ,, \\ Robertus J. M. Klein Gebbink, ${ }^{* \dagger}$ and Gerard van Koten ${ }^{*}, \dagger$ \\ Contribution from the Faculty of Science, Organic Chemistry and Catalysis, Utrecht University, \\ Padualaan 8, 3584 CH, Utrecht, The Netherlands, Faculty of Science, Inorganic Chemistry and \\ Catalysis, Utrecht University, Sorbonnelaan 16, 3584 CA, Utrecht, The Netherlands, and \\ Laboratory of Inorganic Chemistry, ETH Zürich, Hönggerberg, CH-8093, Zürich, Switzerland \\ Received January 12, 2006; E-mail: r.j.m.kleingebbink@chem.uu.nl; g.vankoten@chem.uu.nl; pregosin@inorg.chem.ethz.ch
}

\begin{abstract}
Ionic core-shell dendrimers with an octacationic core have been applied as noncovalent supports for homogeneous catalysts. Catalytically active arylpalladium complexes, which bear a tethered sulfato group, were noncovalently attached to the ionic core-shell dendritic supports via a straightforward ionexchange reaction under mild conditions. Diagnostic shifts in ${ }^{1} \mathrm{H}$ NMR and Overhauser contacts show that the sulfato groups of the catalysts are located close to the octacationic core of the dendritic support in the resulting assemblies. The location of the catalytic $\mathrm{Pd}(\mathrm{II})$ sites has been varied via two strategies: by increasing the dendrimer generation and/or by shortening of the sulfato tether. In addition, a metallodendritic assembly was prepared, which bears an alternative shell of apolar dodecyl groups. Both the dendrimer size and the nature of the dendritic shell have no influence on the binding properties of the dendritic supports, i.e., the octacationic dendrimers of generations $1-3$ form discrete $1: 8$ assemblies with the arylpalladium complexes. The structural aspects and the nature of the metallodendritic assemblies have been studied by means of pulse gradient spin-echo NMR diffusion methods, Overhauser spectroscopy, and electron microscopy (TEM). These techniques showed that the dendritic supports and arylpalladium complexes are strongly associated in solution to give unimolecular assemblies of nanoscopic dimensions. Membrane dialysis can recover these metallodendritic assemblies due to their nanoscopic size. The catalytic performances of the metallodendritic assemblies are comparable, but slightly lower than the performance of the unsupported catalyst.
\end{abstract}

\section{Introduction}

In the past decade many research groups have been involved in the synthesis and application of dendrimer-supported homogeneous catalysts. ${ }^{1,2}$ The nanoscopic size of the dendrimer support facilitates recovery of the catalyst, for example, by means of nanofiltration. ${ }^{3}$ Furthermore, the high solubility and monodisperse structure of the dendritic support allow for the formation of well-defined supported homogeneous catalysts, which can be characterized and studied in situ by various standard analysis techniques. In the reported systems, the homogeneous catalyst, which is often a transition metal complex, is attached to a dendritic support either via a covalent or a dative bond. To reduce the chance of metal leaching, a stable covalent

†trecht University, Faculty of Science, Organic Chemistry and Catalysis.

¥ Utrecht University, Faculty of Science, Inorganic Chemistry and Catalysis.

$\S$ ETH Zürich.

II Current address: Inorganic Chemistry Department, Faculdad de Química, Universidad de Murcia, Apdo. 4021, 30071, Murcia, Spain.

(1) For recent reviews on dendrimer-supported homogeneous catalysts see, for example: (a) van Heerbeek, R.; Kamer, P. C. J.; van Leeuwen, P. W. M. N.; Reek, J. N. H. Chem. Rev. 2002, 102, 3717-3756. (b) Kreiter, R.; Kleij, A. W.; Klein Gebbink, R. J. M.; van Koten, G. Top. Curr. Chem. 2001, 217, 163-199. (c) Astruc, D.; Chardac, F. Chem. Rev. 2001, 101, $2991-3023$ bond between the metal and the dendrimer would be preferable. Functionalization of a dendritic structure using covalent bonds, however, often requires harsh reaction conditions and, as a consequence, calls for dendritic supports with sufficient chemical and thermal stability.

(2) Some recent examples of dendritic catalysts include: (a) Fujihara, T.; Obora Y.; Tokunaga, M.; Sato, H.; Tsuji, Y. Chem. Commun. 2005, 4526-4528. (b) Helms, B.; Liang, C. O.; Hawker, C. J.; Fréchet, J. M. J. Macromolecules 2005, 38, 5411-5415. (c) Lemo, J.; Heuze, K.; Astruc, D. Org. Lett. 2005, 7, 2253-2256. (d) Garcia-Martinez, J. C.; Lezutekong, R.; Crooks, R. M. J. Am. Chem. Soc. 2005, 127, 5097-5103. (e) Deng, G.-J.; Yi, B.; Huang, Y.-Y.; Tang, W.-J.; He, Y.-M.; Fan, Q.-H. Adv. Synth. Catal. 2004, 346, 1440-1444. (f) Müller, C.; Ackerman, L. J.; Reek, J. N. H.; Kamer, P. C. J.; van Leeuwen, P. W. M. N. J. Am. Chem. Soc. 2004, 126, 14960-14963. (g) Sarkar, A.; Ilankumaran, P.; Kisanga, P.; Verkade, J. G. Adv. Synth. Catal. 2004, 346, 1093-1096. (h) Slagt, M. Q.; Stiriba, S.-E.; Kautz, H. Klein Gebbink, R. J. M.; Frey, H.; van Koten, G. Organometallics 2004 23, 1525-1532. (i) Clouet, A.; Darbre, T.; Reymond, J.-L. Angew. Chem., Int. Ed. 2004, 43, 4612-4615. (j) Angurell, I.; Muller, G.; Rocamora, M. Rossell, O.; Seco, M. Dalton Trans. 2004, 2450-2457. (k) Botman, P. N M.; Amore, A.; van Heerbeek, R.; Back, J. W.; Hiemstra, H.; Reek, J. N. H.; van Maarseveen, J. H. Tetrahedron Lett. 2004, 45, 5999-6002. (1) Liu, L.; Breslow, R. Bioorg. Med. Chem. 2004, 12, 3277-3287. (m) Chanthateyanonth, R.; Alper, H. Adv. Synth. Catal. 2004, 346, 1375-1384. (n) Yi, B.; Fan, Q.-H.; Deng, G.-J.; Li, Y.-M.; Qiu, L.-Q.; Chan, A. S. C. Org. Lett. 2004, 7, 1361-1364. (o) Arink, A. M.; van de Coevering, R. Wieczorek, B.; Firet, J.; Jastrzebski, J. T. B. H.; Klein Gebbink, R. J. M.; van Koten, G. J. Organomet. Chem. 2004, 689, 3813-3819.

(3) For reviews on the use of nanofiltration for catalyst recycling: (a) Dijkstra, H. P.; van Klink, G. P. M.; van Koten, G. Acc. Chem. Res. 2002, 35, 798810. (b) Vankelecom, I. F. J. Chem. Rev. 2002, 102, 3779-3810.

10.1021/ja060079t CCC: $\$ 33.50$ @ 2006 American Chemical Society 


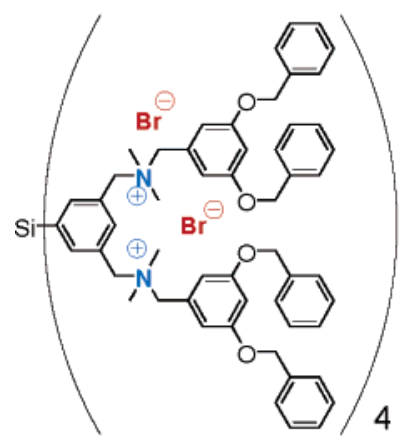

$[1] \mathrm{Br}_{8}$

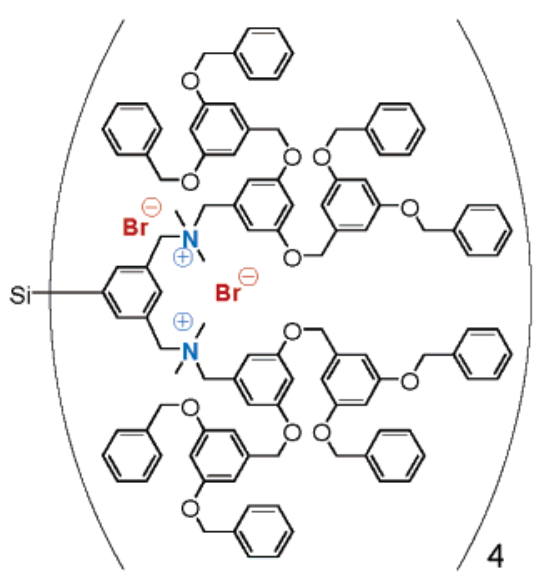

$[2] \mathrm{Br}_{8}$

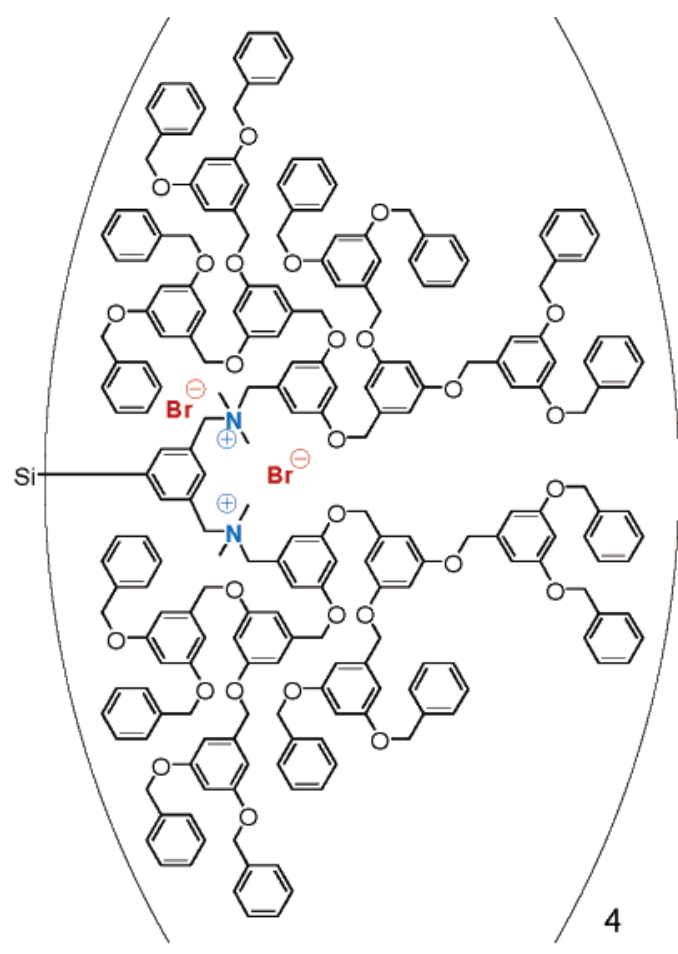

$[3] \mathrm{Br}_{8}$

Figure 1. Ionic core-shell dendrimers $[1] \mathrm{Br}_{8},[2] \mathrm{Br}_{8}$, and $[3] \mathrm{Br}_{8}$, which consist of an octacationic core with eight bromide anions as counterions and a shell of polybenzyl aryl ether dendrons.

The aim of this study is to facilitate the immobilization of catalysts onto a dendritic support under mild conditions by means of reversible noncovalent binding interactions. ${ }^{4,5}$ Ideally, the noncovalent interactions should be sufficiently strong to prevent leaching of the catalyst but should allow for controlled removal of the catalytic moiety from the dendritic support. The reversible nature of the catalyst immobilization could be used to advantage, for example, in case of catalyst deactivation. After removal of the (deactivated) catalyst, the (often expensive) dendritic support can be recovered and, subsequently, reused after reloading it with a fresh batch of the same or a different catalyst.

Recently, our group developed a novel class of ionic coreshell dendrimers, which comprise eight quaternary ammonium sites in the core and a shell of Fréchet-type polybenzyl aryl ether dendrons (Figure 1). ${ }^{6}$ These ionic core-shell dendrimers can be applied as container molecules for (reversible) binding and delivery of various (in)organic substrate molecules. The maximum number of substrate molecules bound by the dendrimers is predefined by the number of cationic sites in their core; i.e., ionic core-shell dendrimers with an octacationic core (Figure 1) can bind a maximum of eight monoanionic substrate molecules. Binding studies revealed that the anionic (anchoring) group of a substrate molecule is located nearby the octacationic

(4) For a recent review on the noncovalent immobilization of catalysts on soluble supports, see: van de Coevering, R.; Klein Gebbink, R. J. M.; van Koten, G. Prog. Polym. Sci. 2005, 30, 474-490.

(5) Recent examples of noncovalent catalyst immobilization on dendrimers include: (a) Ooe, M.; Murata, M.; Mizugaki, T.; Ebitani, K.; Kaneda, K. J. Am. Chem. Soc. 2004, 126, 1604-1605. (b) Plault, L.; Hauseler, A.; Nlate, S.; Astruc, D.; Ruiz, J.; Gatard, S.; Neumann, R. Angew. Chem., Int. Ed. 2004, 43, 2924-2928. (c) de Groot, D.; de Waal, B. F. M.; Reek, J. N. H.; Schenning, A. P. H. J.; Kamer, P. C. J.; Meijer, E. W.; van Leeuwen, P. W. M. N. J. Am. Chem. Soc. 2001, 123, 8453-8458.

(6) Kleij, A. W.; van de Coevering, R.; Klein Gebbink, R. J. M.; Noordman, A. M.; Spek, A. L.; van Koten, G. Chem. Eur. J. 2001, 7, 181-192. core of the dendritic assembly. 6,7 The physical properties, for example the solubility profile, of a dendritic assembly formed between an octacationic dendrimer and anionic substrate molecules is influenced by the nature of the dendritic shell, as was shown for dendritic assemblies formed by dendritic entity $[4]^{8+}$ (Figure 2). ${ }^{8}$ Due to the nanoscopic size of these ionic core-shell dendrimers, their corresponding dendritic assemblies can be easily recovered by means of dialysis.

To attach homogeneous catalysts to these octacationic dendrimers, aryl palladium complexes $[\mathbf{5}]^{-},\left[[\mathbf{5 a}]\left[\mathrm{BF}_{4}\right]\right]^{-},[\mathbf{6}]^{-}$, and $\left[[6 \mathbf{6}]\left[\mathrm{BF}_{4}\right]\right]^{-}$with an anionic anchoring group were developed earlier. ${ }^{9}$ These complexes bear a catalytic site, either a neutral $\mathrm{NCN}-\mathrm{Pd}-\mathrm{Cl}$ or a cationic $\left[\mathrm{NCN}-\mathrm{Pd}\left(\mathrm{OH}_{2}\right)\right]^{+}$group, ${ }^{10-12}$ and a tethered anionic anchoring site, i.e., a sulfato group (Figure 3).

The monoanionic $\mathrm{NCN}$-pincer ligand $(\mathrm{NCN}=2,6$-bis[(dimethylamino)methyl]phenyl anion) coordinates to $\mathrm{d}^{8}$ transition metals via a covalent carbon-metal bond, which is further stabilized by two dative bonds between the nitrogen donor atoms and the metal. ${ }^{13}$ The mer-N,C,N-terdentate binding mode prevents leaching of the metal atom from the ligand. The NCNpincer $\mathrm{Pd}(\mathrm{II})$ moiety is connected to the sulfato group by an

(7) van de Coevering, R.; van Koten, G.; Klein Gebbink, R. J. M. Manuscript in preparation.

(8) van de Coevering, R.; van Koten, G.; Klein Gebbink, R. J. M. Manuscript in preparation.

(9) van de Coevering, R.; Kuil, M.; Lutz, M.; Spek, A. L.; Klein Gebbink, R. J. M.; van Koten, G. Organometallics 2005, 24, 6147-6158.

(10) Mehendale, N. C.; Klein Gebbink, R. J. M.; van Koten, G. Manuscript in preparation.

(11) Schlenk, C.; Kleij, A. W.; Frey, H.; van Koten, G. Angew. Chem., Int. Ed. 2000, 39, 3445-3447.

(12) Dijkstra, H. P.; Slagt, M. Q.; McDonald, A.; Kruithof, C. A.; Kreiter, R.; Mills, A. M.; Lutz, M.; Spek, A. L.; Klopper, W.; van Klink, G. P. M.; van Koten, G. Eur. J. Inorg. Chem. 2003, 830-838.

(13) Albrecht, M.; van Koten, G. Angew. Chem., Int. Ed. 2001, 40, 37503781 


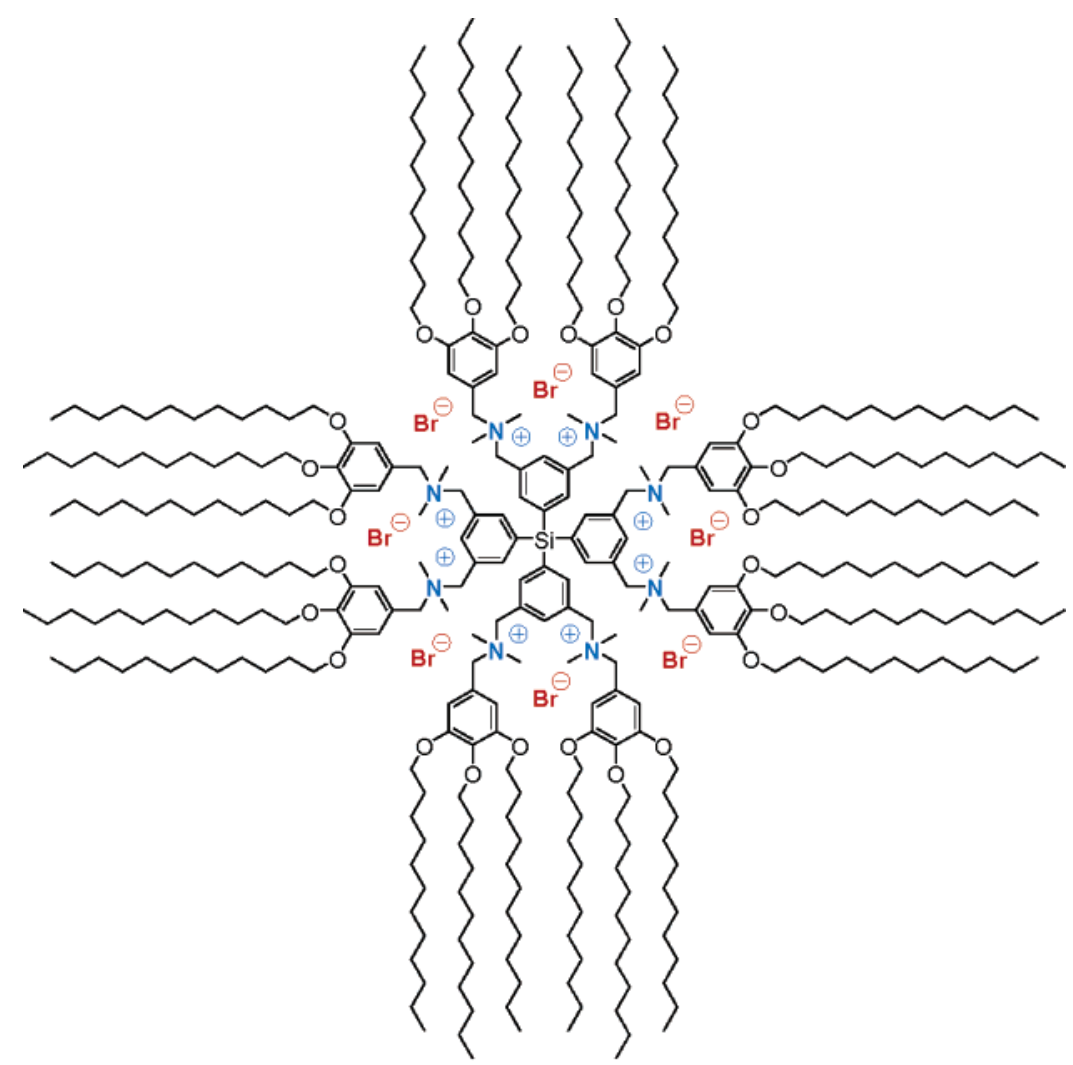

$[4] \mathrm{Br}_{8}$

Figure 2. Ionic core-shell dendrimer [4] $\mathrm{Br}_{8}$, which consists of an octacationic core with eight bromide counterions and an outer shell of apolar dodecyl groups.

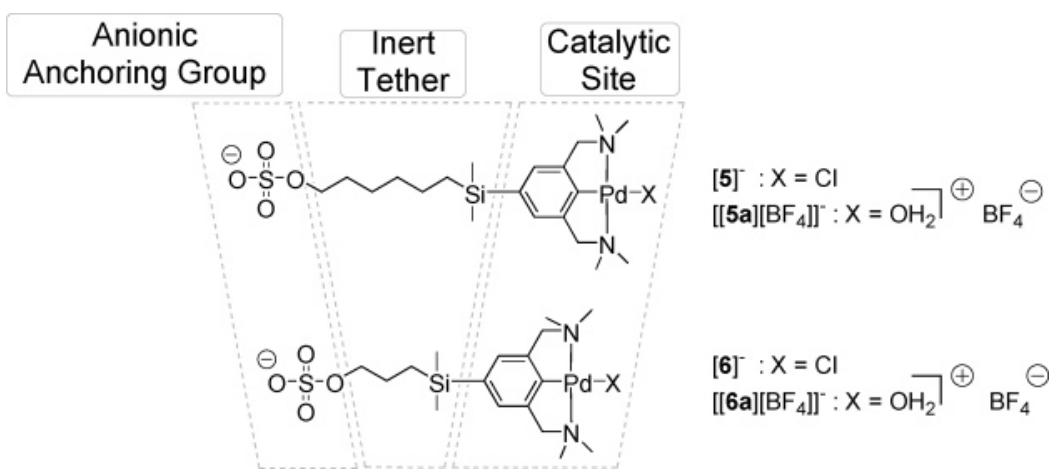

Figure 3. Design of NCN-pincer Pd(II) complexes [5 $]^{-}$and $[\mathbf{6}]^{-}$with a $\mathrm{C}_{6} \mathrm{SiMe}_{2}$ or $_{3} \mathrm{SiMe}_{2}$ tethered sulfato group, respectively, and their corresponding zwitterionic Pd(II) aqua complexes $\left[[\mathbf{5 a}]\left[\mathrm{BF}_{4}\right]\right]^{-}$and $\left[[\mathbf{6 a}]\left[\mathrm{BF}_{4}\right]\right]^{-}$.

inert $\mathrm{Si}$-alkanediyl tether of variable length, which is either a $\mathrm{C}_{6} \mathrm{SiMe}_{2}$ group $\left([\mathbf{5}]^{-}\right.$and $\left[[\mathbf{5 a}]\left[\mathrm{BF}_{4}\right]\right]^{-}$) or a shorter $\mathrm{C}_{3} \mathrm{SiMe}_{2}$ group $\left([\mathbf{6}]^{-}\right.$and $\left.\left[[\mathbf{6 a}]\left[\mathrm{BF}_{4}\right]\right]^{-}\right)$.

Here, we have investigated the application of the different generations and kinds of octacationic core-shell dendrimers as noncovalent supports for these types of $\mathrm{Pd}(\mathrm{II})$ complexes. Through a detailed analysis of the physical and catalytic properties of the metallodendritic assemblies, two strategies to vary the relative location of catalytic sites within the dendritic assemblies were investigated (Figure 4).

In the first strategy, the dendrimer generation was increased from the first to the third generation in order to increase the "thickness" of the dendritic shell and, thereby, to enfold the catalytic sites (Figure 4, strategy I). The second strategy involved the shortening of the tether between the catalytic site and anionic anchoring site of the homogeneous catalyst (Figure 4, strategy II). A short tether would "pull" the catalytic site closer to the cationic anchoring site in the core of the assembly and, depending on the thickness of the dendritic shell, into the voids of the dendritic support. Interestingly, encapsulated catalytic sites could experience an effect from the nano environment of the internal voids of a dendritic structure, which would influence the catalytic performance. ${ }^{14}$

\section{Results}

Initial Investigation on First-Generation Dendrimers. Our initial efforts in the synthesis of catalytic metallodendritic

(14) (a) Brunner, H. J. Organomet. Chem. 1995, 500, 39-46. (b) Seebach, D.; Rheiner, P. B.; Greiveldinger, G.; Butz, T.; Sellner, H. Top. Curr. Chem. 1998, 197, 125-164. 


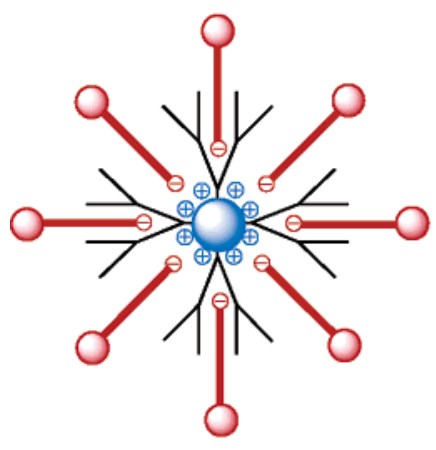

'Exposed' Catalytic Sites
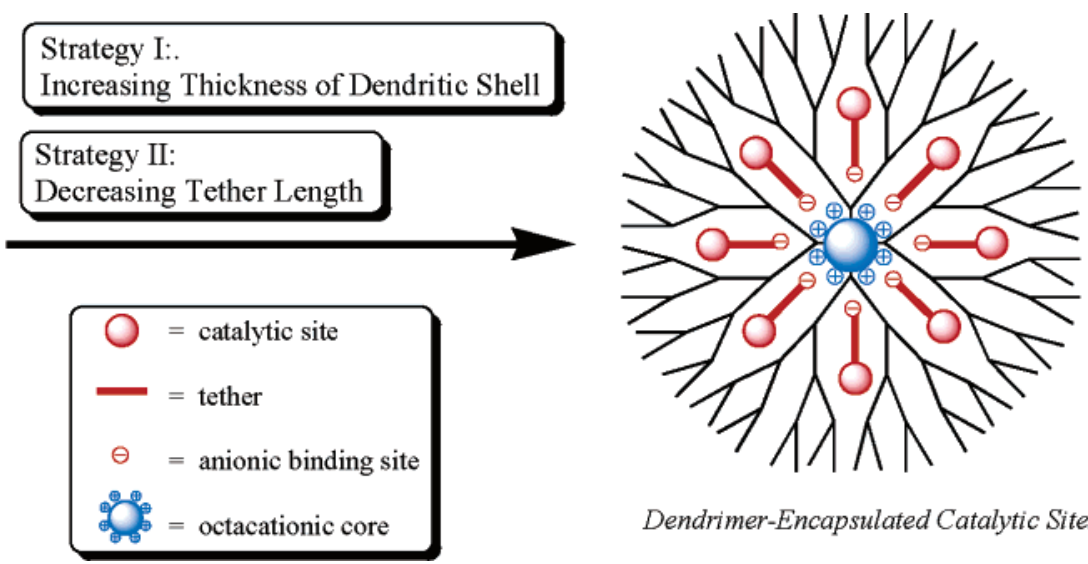

Dendrimer-Encapsulated Catalytic Sites

Figure 4. Two strategies to vary the location of the catalytic metal sites from the outside (left) or inside (right) of the metallodendritic structure.

assemblies focused on the first-generation dendrimer $[\mathbf{1}]^{8+}$ and the incorporation of a catalytic moiety with a positively charged Pd center. ${ }^{15}$ Two synthetic routes were developed for this purpose. The first synthetic route (Scheme 1, route A) starts with the noncovalent attachment of the monoanionic $\mathrm{Pd}(\mathrm{II})$ complex $[\mathbf{5}]^{-}$to octacationic entity $[\mathbf{1}]^{8+}$ and was performed via an anion exchange reaction between the bromide anions of octaionic dendrimer [1] $\mathrm{Br}_{8}$ and [5] $]^{-}$in dichloromethane. Isolation of metallodendritic assembly $[\mathbf{1}][\mathbf{5}]_{8}$ was achieved through aqueous washings and passive dialysis. ${ }^{16}[\mathbf{1}][\mathbf{5}]_{8}$ was then treated with $\mathrm{AgBF}_{4}$ in wet acetone to abstract the chloride ligands from the arylpalladium fragments.

In an alternative synthesis (Scheme 1 , route B), the bromide anions of dendrimer $[1] \mathrm{Br}_{8}$ were first exchanged for $\mathrm{BF}_{4}$ anions by treatment with excess of $\mathrm{NaBF}_{4}$ in a biphasic setup $\left(\mathrm{CH}_{2}-\right.$ $\left.\mathrm{Cl}_{2} / \mathrm{H}_{2} \mathrm{O}\right)$ to afford $[\mathbf{1}]\left[\mathrm{BF}_{4}\right]_{8}$. Treatment of $[\mathbf{1}]\left[\mathrm{BF}_{4}\right]_{8}$ with 8.0 equiv of zwitterionic $\mathrm{Pd}(\mathrm{II})$ aqua complex [5a] (devoid of counterions $)^{9}$ afforded $[\mathbf{1}][\mathbf{5} \mathbf{a}]_{8}\left[\mathrm{BF}_{4}\right]_{8}$. The assembly prepared via route $\mathrm{B}$ showed very similar spectroscopic analyses as the assembly formed via route A (Scheme 1). A distinction was found in the ${ }^{1} \mathrm{H}$ NMR spectra, where the line widths at halfheight of $\mathrm{Pd}(\mathrm{II})$ complex [5a] of the assembly obtained via route $\mathrm{B}$ were twice as narrow as those of the metallodendritic assembly obtained via route A.

The catalytic performance of metallodendritic $[\mathbf{1}][\mathbf{5}]_{8}$ and the two $[\mathbf{1}][\mathbf{5 a}]_{8}\left[\mathrm{BF}_{4}\right]_{8}$ assemblies were tested in the aldol condensation reaction between benzaldehyde and methyl isocyanoacetate (reaction 1) and compared with those of $\mathrm{NCN}-\mathrm{PdCl}$

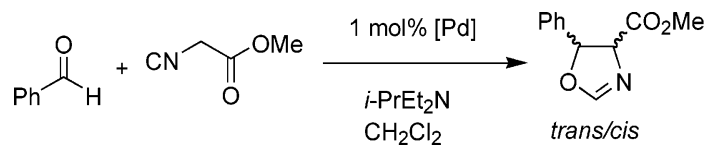

complex $\left[\mathrm{NBu}_{4}\right][\mathbf{5}]$, of $\mathrm{Pd}(\mathrm{II})$ aqua complexes $\left[\mathrm{NBu}_{4}\right][\mathbf{5 a}]\left[\mathrm{BF}_{4}\right]$ and $\left.\left[t-\mathrm{BuMe} \mathrm{MiO}_{2} \mathrm{SiO} \mathrm{CH}_{2}\right)_{6} \mathrm{NCNPd}\left(\mathrm{OH}_{2}\right)\right]\left[\mathrm{BF}_{4}\right]\left([\mathbf{7 a}]\left[\mathrm{BF}_{4}\right]\right)$, and of zwitterionic $\mathrm{Pd}(\mathrm{II})$ aqua complex [5a] (Table 1). Reaction 1 enables a comparison of the catalytic activity as well as the product selectivity, in terms of cis and trans oxazoline products, of the Pd(II) complexes. ${ }^{17}$

(15) van de Coevering, R.; Kuil, M.; Klein Gebbink, R. J. M.; van Koten, G. Chem. Commun. 2002, 1636-1637.

(16) Commercially available dialysis membrane (benzoylated cellulose, SIGMA) was used, which separates compounds with molecular weights higher than $2000 \mathrm{~g} / \mathrm{mol}$ from compounds with molecular weights equal to or lower than $1200 \mathrm{~g} / \mathrm{mol}$.
Table 1. Catalytic Performance of Dendrimer-Supported and Unsupported Pd(II) Complexes in the Aldol Condensation Reaction between Methyl Isocyanoacetate and Benzaldehyde ${ }^{a}$

\begin{tabular}{|c|c|c|c|}
\hline assembly & TOF $^{b}$ & $\begin{array}{c}\text { conversion } \\
(\%)\end{array}$ & $\begin{array}{l}\operatorname{trans} \\
(\%)^{c}\end{array}$ \\
\hline$[\mathbf{1}][\mathbf{5}]_{8}$ & 17 & $82^{d}$ & 69 \\
\hline$\left[\mathrm{NBu}_{4}\right][5]$ & 12 & $95^{d}$ & 72 \\
\hline$[\mathbf{1}][\mathbf{5 a}]_{8}\left[\mathrm{BF}_{4}\right]_{8}$ (route a) & 51 & $100^{e}$ & 58 \\
\hline$\left[\mathrm{NBu}_{4}\right][\mathbf{5 a}]\left[\mathrm{BF}_{4}\right]$ & 55 & $100^{e}$ & 58 \\
\hline$[1][5 \mathbf{a}]_{8}\left[\mathrm{BF}_{4}\right]_{8}($ route $\mathbf{b})$ & 29 & $60^{e}$ & 60 \\
\hline [5a] & 28 & $64^{e}$ & 63 \\
\hline$[7 \mathbf{a}]\left[\mathrm{BF}_{4}\right]$ & 35 & $91^{e}$ & 62 \\
\hline
\end{tabular}

${ }^{a}$ Reactions carried out in $\mathrm{CH}_{2} \mathrm{Cl}_{2}(5 \mathrm{~mL})$ under ambient conditions in the presence of $10 \mathrm{~mol} \%$ of $(i-\operatorname{Pr})_{2} \mathrm{EtN}$ and $1 \mathrm{~mol} \%$ of catalyst in terms of [Pd]. ${ }^{b}$ Turnover frequency (TOF) per hour per [Pd] during the first hour. ${ }^{c}$ Calculated after 24 h. ${ }^{d}$ Calculated after $24 \mathrm{~h}$ by GC analysis using dodecane as an internal standard. ${ }^{e}$ Calculated after $5 \mathrm{~h}$ by specific ${ }^{1} \mathrm{H}$ NMR spectroscopy signal integration using mesitylene as an internal standard.

Metallodendritic assembly $[\mathbf{1}][\mathbf{5}]_{8}$ and unsupported NCN$\mathrm{PdCl}$ complex $\left[\mathrm{NBu}_{4}\right][5]$ showed comparable initial turnover frequencies (TOF) and similar product distributions. The Pd(II) aqua complexes $[\mathbf{1}][\mathbf{5 a}]_{8}\left[\mathrm{BF}_{4}\right]_{8}$ (route $\mathrm{A}$ ) and $\left[\mathrm{NBu}_{4}\right][\mathbf{5 a}]-$ $\left[\mathrm{BF}_{4}\right]$ showed initial TOFs around 3 times higher than their $\mathrm{NCN}-\mathrm{PdCl}$ analogues. Remarkably, metallodendritic assembly $[\mathbf{1}][\mathbf{5 a}]_{8}\left[\mathrm{BF}_{4}\right]_{8}$ prepared via route $\mathrm{B}$ exhibits a lower catalytic activity $(\mathrm{TOF}=29)$ than the assembly prepared via route $\mathrm{A}$ $(\mathrm{TOF}=51)$. The catalytic performance of $[\mathbf{1}][\mathbf{5} \mathbf{a}]_{8}\left[\mathrm{BF}_{4}\right]_{8}$ prepared by route $\mathrm{B}$ is similar to that of the unsupported zwitterionic $\mathrm{Pd}(\mathrm{II})$ aqua complex [5a] that is devoid of ammonium as well as of $\mathrm{BF}_{4}^{-}$ions. In addition, $\mathrm{Pd}(\mathrm{II})$ complex $[7 \mathbf{a}]\left[\mathrm{BF}_{4}\right]$, which bears a neutral para substituent, was tested on its catalytic performance to study the influence of the anionic group of [5a]. $\mathrm{Pd}(\mathrm{II})$ complex $[\mathbf{7} \mathbf{a}]\left[\mathrm{BF}_{4}\right]$ displayed a catalytic activity $(\mathrm{TOF}=35)$ that is somewhat higher than that of [5a] but substantially lower than the catalytic activity observed for $\left[\mathrm{NBu}_{4}\right][\mathbf{5} \mathbf{a}]\left[\mathrm{BF}_{4}\right]$.

This initial study showed the important role of the anionic sulfato group, the $\mathrm{BF}_{4}$ anion, and of ammonium cations on the catalytic activity of zwitterionic Pd(II) aqua complex [5a]. In a

(17) (a) Longmire, J. M.; Zhang, X.; Shang, M. Organometallics 1998, 17 4374-4379. (b) Stark, M. A.; Richards, C. J. Tetrahedron Lett. 1997, 38, 5881-5884. (c) Nesper, R.; Pregosin, P. S.; Püntener, K.; Wörle, M.; Albatini, A. J. Organomet. Chem. 1996, 507, 85-101. (d) Gorla, F.; Togni, A.; Venanzi, L. M.; Albinati, A.; Lianza, F. Organometallics 1994, 13, 1607-1616. (e) Nesper, R.; Pregosin, P. S.; Püntener, K.; Wörle, M. Helv. Chim. Acta 1993, 76, 2239-2249. (f) Hasyashi, T.; Sawamura, M.; Ito, Y. Tetrahedron 1992, 48, 1999-2021. 
Scheme 1. Synthesis of Metallodendritic Assembly $\left.[1]_{[5}\right]_{8}$ and Its Corresponding Dendritic Pd(II) Aqua Assembly $\left.[1]_{[5 a}\right]_{8}\left[B F_{4}\right]_{a}{ }^{a}$

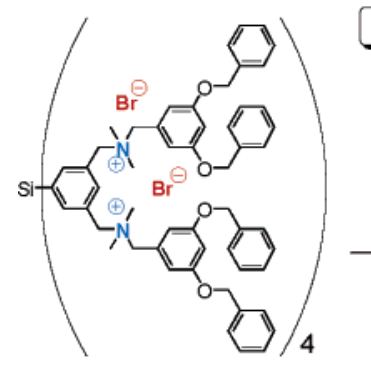

$[1] \mathrm{Br}_{8}$

ROUTE B

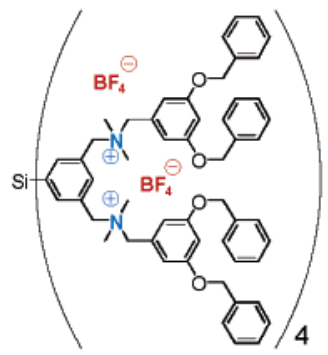

$[1]\left[\mathrm{BF}_{4}\right]_{8}$

ROUTE A

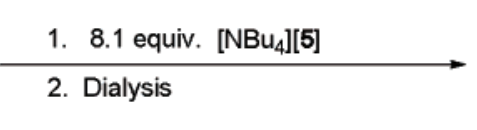

8.0 equiv. [5a]
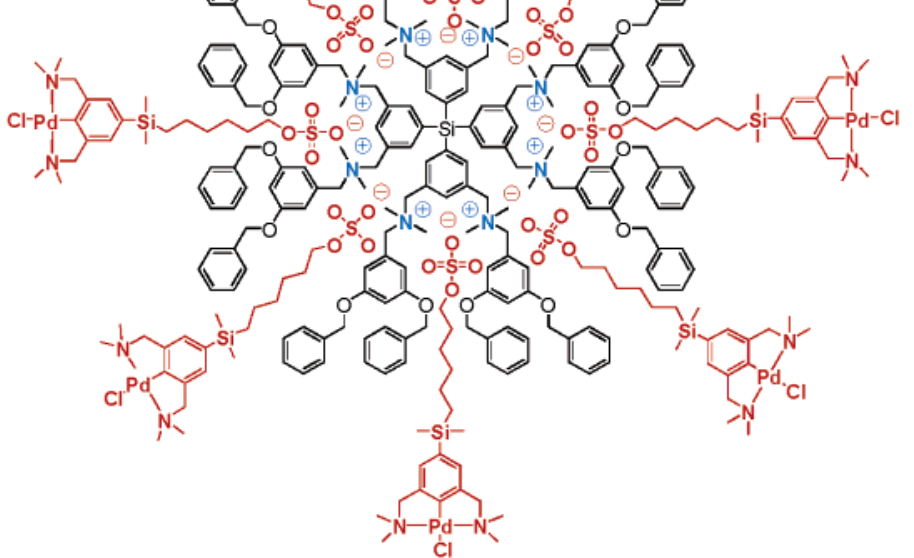

$[1][5]_{8}$
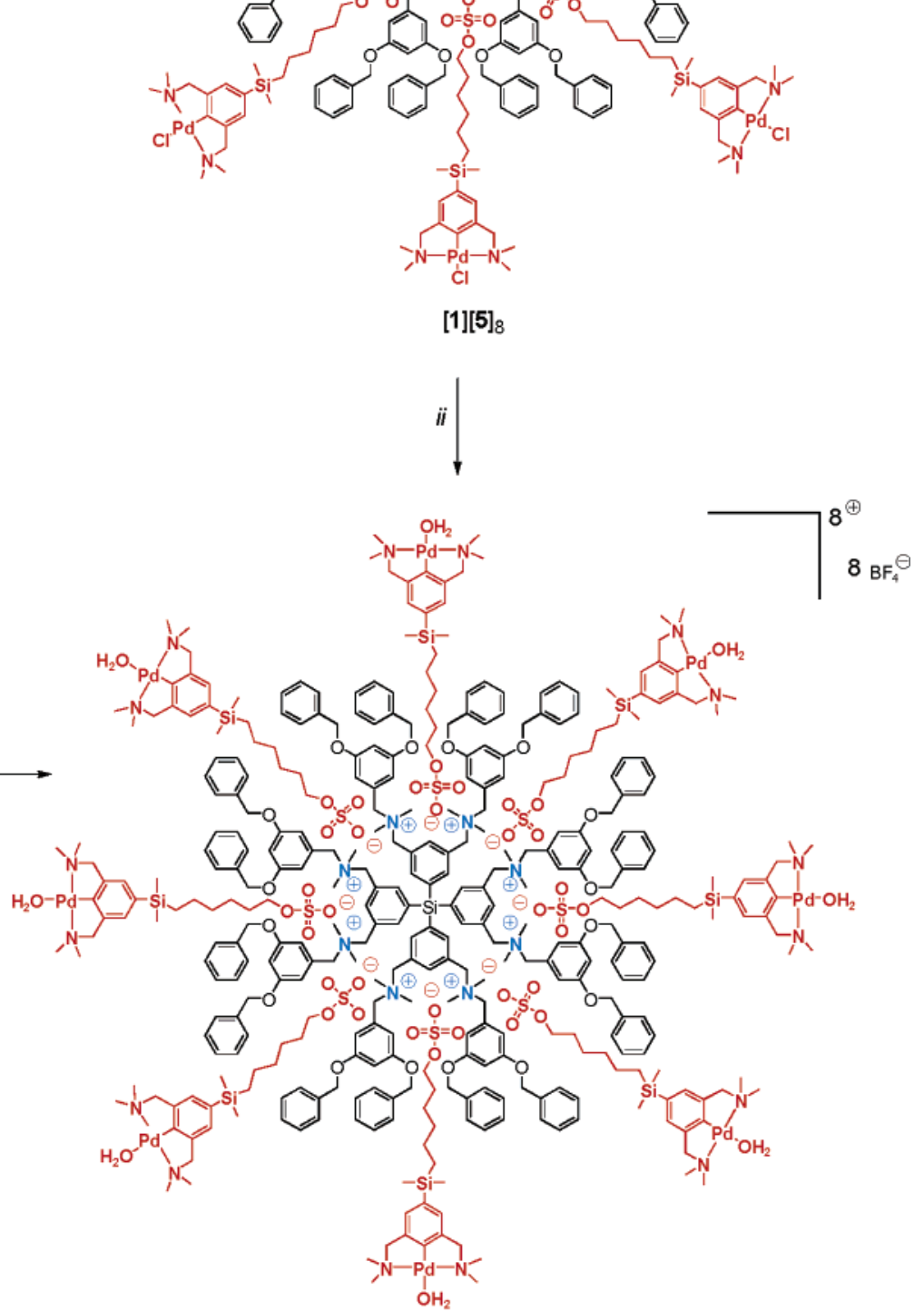

[1] $\left[\mathrm{Fa}_{8}\left[\mathrm{BF}_{4}\right]_{8}\right.$

${ }^{a}$ Reagents and conditions: (i) excess of $\mathrm{NaBF}_{4}, \mathrm{CH}_{2} \mathrm{Cl}_{2}, \mathrm{H}_{2} \mathrm{O}$; (ii) 8.0 equiv of $\mathrm{AgBF}_{4}$, wet acetone.

recent study, we have investigated the physical properties of these species in more detail to understand the role of ion pairing on their physical properties. ${ }^{9}$ An important conclusion of this study was that the zwitterionic Pd(II) complex can stabilize itself intermolecularly without counterions. In case of metallodendritic assembly $[\mathbf{1}][\mathbf{5 a}]_{8}\left[\mathrm{BF}_{4}\right]_{8}$, this could lead to a rearrangement of the assembly, which can give unsupported [5a]. The similar catalytic activities of zwitterionic $\mathrm{Pd}(\mathrm{II})$ complex [5a] and dendritic assembly $[\mathbf{1}][\mathbf{5 a}]_{8}\left[\mathrm{BF}_{4}\right]_{8}$ prepared via route $\mathrm{B}$ strongly indicate that a significant amount of unsupported zwitterionic $\mathrm{Pd}(\mathrm{II})$ complex is formed during this synthetic procedure. On the contrary, the higher catalytic activity of assembly $[\mathbf{1}][\mathbf{5 a}]_{8^{-}}$ 
$\left[\mathrm{BF}_{4}\right]_{8}$ prepared via route $\mathrm{A}$ points to the fact that unsupported zwitterionic complexes are not formed, or are formed to a lesser extent, via this synthetic protocol.

To prevent formation of (unsupported) zwitterionic species, and, therefore, to be able to study the properties of discrete dendritic assemblies, we have continued our study with metallodendritic assemblies that bear the $\mathrm{NCN}-\mathrm{Pd}$ halide complexes $[5]^{-}$and $[6]^{-}$. Recent mechanistic studies on NCN$\mathrm{PdCl}$ complexes in the aldol condensation reaction revealed that these complexes react with methyl isocyanoacetate to give neutral catalytically active $\mathrm{Pd}$ (II) species and that "activation" of the Pd complex by halide abstraction is, therefore, not required..$^{10}$

Synthesis of the Metallodendritic Assemblies. The first-, second-, and third-generation dendritic entities $[\mathbf{1}]^{8+},[2]^{8+}$, and $[3]^{8+}$ (Figure 1), respectively, were used as dendritic support for the noncovalent binding of $\mathrm{NCN}-\mathrm{PdCl}$ complexes [5] $]^{-}$and $[6]^{-}$(see Figure 3), yielding a series of six different metallodendritic assemblies (Figure 5). In addition, dendritic entity [4] ${ }^{8+}$ (Figure 2), which bears an apolar outer shell of dodecyl groups, was used as a support for $[6]^{-}$. The noncovalent attachment of the Pd(II) complexes to the octacationic entities was performed according to the synthetic procedure outlined for $[\mathbf{1}][\mathbf{5}]_{8}$. The dendrimers and Pd complexes were mixed in dichloromethane, followed by aqueous washings and passive dialysis ${ }^{16}$ in order to remove formed $\left[\mathrm{NBu}_{4}\right] \mathrm{Br}$ and to remove excess of the unsupported $\left[\mathrm{NBu}_{4}\right]$ salts of the Pd complexes, which were found to permeate through the dialysis membrane unlike the ionic core-shell dendrimers and their corresponding assemblies.

In the dialysis experiments, mixtures of dichloromethane and acetone were used since polar solvents enhance the performance of the dialysis membrane. ${ }^{18}$ The reaction mixtures were transferred into the membrane tubing and dialyzed one to four times for $4 \mathrm{~h}$ against acetone, acetone/dichloromethane, or wet dichloromethane. The choice of solvent was determined by the solubility properties of the metallodendritic assembly. All metallodendritic assemblies appeared soluble in dichloromethane, while their solubility in acetone decreases on going from the first to the third generation. After dialysis, the content of the tubing was concentrated in vacuo to afford the metallodendritic assemblies as foamy, off-white solids in 66-100\% yield. The acceptor phases outside the membrane tubings contained $\left[\mathrm{NBu}_{4}\right]$ [5] or $\left[\mathrm{NBu}_{4}\right][6]$ and small quantities of the metallodendritic assemblies as was shown by NMR. In case of metallodendritic assembly $[4][6]_{8}$ an additional purification step by size exclusion chromatography was required to effectively separate the metallodendritic assembly from excess of $\left[\mathrm{NBu}_{4}\right][6]$, which yielded $[4][6]_{8}$ as a foamy, off-white solid in $49 \%$ yield. In contrast with the metallodendritic assemblies with a polybenzyl aryl ether shell, metallodendritic assembly $[4][6]_{8}$ is soluble in apolar organic solvents such as hexane.

Stoichiometries of the Metallodendritic Assemblies. The stoichiometry of the metallodendritic assemblies, i.e., the ratio between the octacationic dendritic supports $[\mathbf{1}]^{8+},[2]^{8+},[3]^{8+}$, and $[4]^{8+}$ and the $\mathrm{Pd}(\mathrm{II})$ complexes $[5]^{-}$and $[\mathbf{6}]^{-}$, was analyzed by ${ }^{1} \mathrm{H}$ NMR spectroscopy. Specific peak integrals showed the octacationic dendritic entities and the anionic $\mathrm{Pd}(\mathrm{II})$ complexes

(18) Although the membrane tubing (ref 17) can be used for dialysis purposes in less polar solvents such as dichloromethane, it was originally developed for dialysis in aqueous phase solutions. in 1:8 ratios (Table $\mathrm{S} 1$ in the Supporting Information). Peaks corresponding to the tetrabutylammonium cation were absent for all assemblies after dialysis.

To verify the determined stoichiometry, a stepwise buildup of the assemblies was performed in biphasic setups. NMR analysis of these experiments confirmed that in all cases a maximum number of eight $\mathrm{Pd}(\mathrm{II})$ complexes can be linked to the octacationic dendritic entities. When an excess of $\left[\mathrm{NBu}_{4}\right]-$ [5] or $\left[\mathrm{NBu}_{4}\right][6]$ was added to the octaionic dendrimers no additional $\mathrm{Pd}(\mathrm{II})$ complexes were bound.

Further evidence for the proposed stoichiometry of the metallodendritic assemblies was provided by mass spectrometry (nano-ESI-MS). For all assemblies, characteristic fragment ion peaks were observed which were in agreement with the 1:8 stoichiometry suggested by NMR. Analysis of the spectra was complicated by the fact that halide scrambling $(\mathrm{Cl} / \mathrm{Br})$ occurred at $\mathrm{Pd}$. The average ratios between bromide and chloride ligands varied between 4:4 and 6:2, depending on the metallodendritic assembly. Halide scrambling was not shown by the elemental analysis data of the metallodendritic assemblies. In all cases, the elemental analyses match with molecular assemblies bearing eight chloride atoms. It should be mentioned that for the higher generations halide scrambling would cause relatively small differences in the $\mathrm{C}, \mathrm{H}$, and $\mathrm{N}$ analysis. The elemental analyses of the third-generation assemblies, for example, match with metallodendritic assemblies with $\mathrm{Cl} / \mathrm{Br}$ ratios of 6 to 2 .

A typical nano-ESI spectrum for this class of metallodendritic assemblies is shown for $[2][5]_{8}$ in Figure 6. This spectrum shows characteristic fragment ion peaks for $[2][5]_{8}(\mathrm{Cl} / \mathrm{Br}=$ 2/6: $\left.M_{\mathrm{W}}=11447.14\right)$, e.g., at $\mathrm{m} / \mathrm{z}, 3751.6$ (3750.6 calcd for $\left.[\mathrm{M}-\mathrm{Cl}-2 \mathrm{Br}]^{3+}\right), 3395.1$ (3393.9 calcd for $\left[\mathrm{M}-2\left[\mathrm{O}_{3} \mathrm{SO}-\right.\right.$ $\left.\left.\left.\left(\mathrm{CH}_{2}\right)_{6} \mathrm{SiMe}_{2} \mathrm{NCNPdBr}\right]-\mathrm{Cl}\right]^{3+}\right), 3216.5$ (3215.5 calcd for $\left[\mathrm{M}-\left[\mathrm{O}_{3} \mathrm{SO}\left(\mathrm{CH}_{2}\right)_{6} \mathrm{SiMe}_{2} \mathrm{NCNPdCl}\right]-2\left[\mathrm{O}_{3} \mathrm{SO}\left(\mathrm{CH}_{2}\right)_{6} \mathrm{SiMe}_{2}-\right.\right.$ $\mathrm{NCNPdBr}]^{3+}$ ), 2392.4 (2391.7 calcd for $\left[\mathrm{M}-3\left[\mathrm{O}_{3} \mathrm{SO}\left(\mathrm{CH}_{2}\right)_{6^{-}}\right.\right.$ $\left.\left.\mathrm{SiMe}_{2} \mathrm{NCNPdBr}\right]-\mathrm{Cl}\right]^{4+}$ ), and 535.4 (536.1 calcd for $\left[\mathrm{HO}_{3}-\right.$ $\left.\left.\mathrm{SO}\left(\mathrm{CH}_{2}\right)_{6} \mathrm{SiMe}_{2} \mathrm{NCNPd}\right]^{+}\right)$. These peaks represent cations formed from $[2][5]_{8}$ upon loss of three halide ions, two anions $\mathbf{5}$ plus a halide ion, three anions $\mathbf{5}$, and three anions $\mathbf{5}$ plus a halide ion, respectively. Unfortunately, we were not able to obtain a mass spectrum of the third-generation metallodendritic assemblies $[3][5]_{8}$ and $[3][6]_{8}$ due to precipitation of the assemblies during ESI-MS analysis.

Structural Analysis Using Various NMR Techniques. In the ${ }^{1} \mathrm{H}$ NMR spectra of the metallodendritic assemblies diagnostic shifts were observed compared to the spectra of the octaionic dendrimers $[1] \mathrm{Br}_{8}-[4] \mathrm{Br}_{8}$ (Figure S1a in the Supporting Information) and $\mathrm{Pd}(\mathrm{II})$ complexes $\left[\mathrm{NBu}_{4}\right][5]$ and $\left[\mathrm{NBu}_{4}\right][6]$ (Figure $\mathrm{S} 1$, parts $\mathrm{b}$ and $\mathrm{c}$ in the Supporting Information). Shifts to lower frequencies $(0.2-0.5 \mathrm{ppm})$ were found for protons nearby the ammonium sites in the core of the dendritic supports, i.e., $\mathrm{NMe}_{2}$ and benzylic protons of the ammonium groups, and aryl groups of the inner part of the dendritic shell. On the contrary, shifts to higher frequencies $(0.08-0.56 \mathrm{ppm})$ were observed for the aryl protons of the tetraphenylsilane group in the core unit. The shifts to lower frequencies observed for the protons near the ammonium groups decrease by increasing the dendrimer generation, while the shifts to higher frequencies found for the protons of the tetraphenylsilane in the core unit increase. 


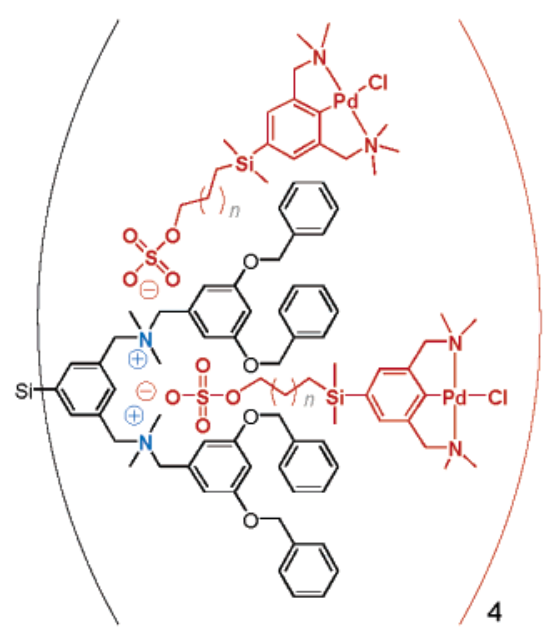

$n=4\left([1][5]_{8}\right)$
$1\left([1][6]_{8}\right)$

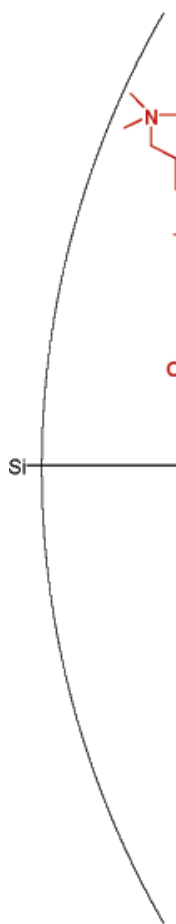

$$
\begin{array}{r}
n=4\left([3][5]_{8}\right) \\
1\left([3][6]_{8}\right)
\end{array}
$$

Figure 5. Metallodendritic assemblies.

The protons of $\mathrm{Pd}(\mathrm{II})$ complex [5] $]^{-}$showed shifts to lower frequencies in the presence of the dendritic supports. For $[\mathbf{1}][\mathbf{5}]_{8}$, the most pronounced shift was found for the protons of the $\mathrm{CH}_{2-}$ $\mathrm{Si}$ group of the $\mathrm{C}_{6} \mathrm{SiMe}_{2}$ tether unit of [5] $]^{-}(0.13 \mathrm{ppm})$. Upon increasing the dendrimer generation the shifts to lower frequencies of the protons of the tether unit increase. In addition, at higher generations strong shifts to lower frequencies were observed for the $\mathrm{SiMe}_{2}$ group and the NCN moiety. In case of

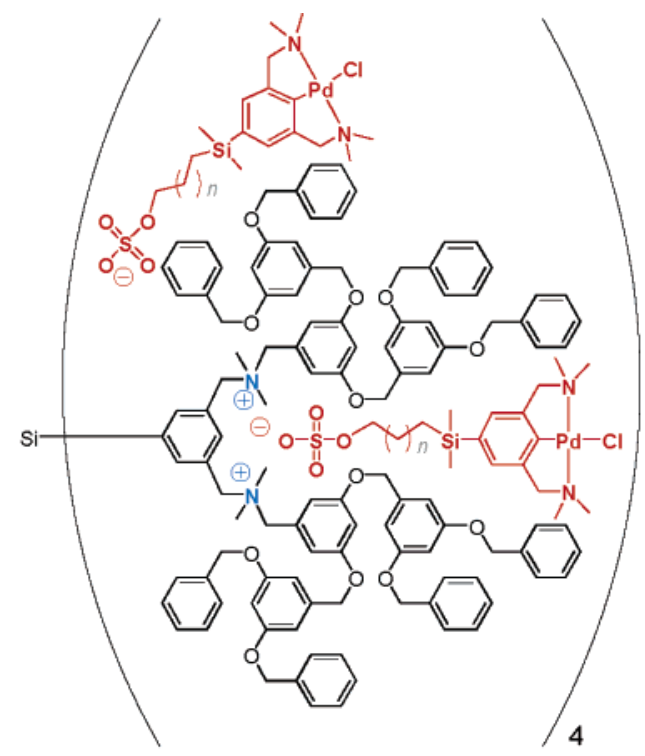

$$
\begin{array}{r}
n=4\left([2][5]_{8}\right) \\
1\left([2][6]_{8}\right)
\end{array}
$$

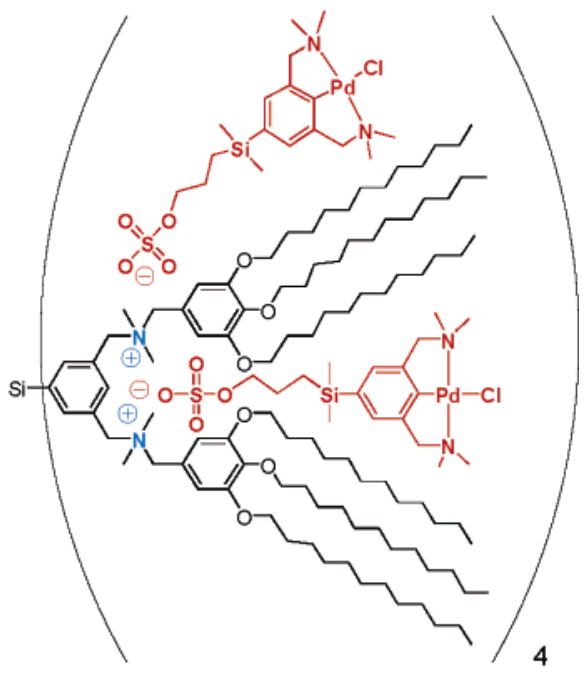

$[4][6]_{8}$ the third-generation metallodendritic assemblies $[3][5]_{8}$ shifts to lower frequencies in the range of $0.12-0.24 \mathrm{ppm}$ were found for the protons of the NCN moiety.

Similar trends were observed in the ${ }^{1} \mathrm{H}$ NMR spectra of the metallodendritic assemblies formed between the octacationic dendrimer and $\mathrm{Pd}(\mathrm{II})$ complex $[6]^{-}$that bears a shorter $\mathrm{C}_{3} \mathrm{SiMe}_{2}$ tether. The changes in chemical shift values observed for the $\mathrm{C}_{3} \mathrm{SiMe}_{2}$ tether unit and the NCN moiety of $[6]^{-}$are, however, 


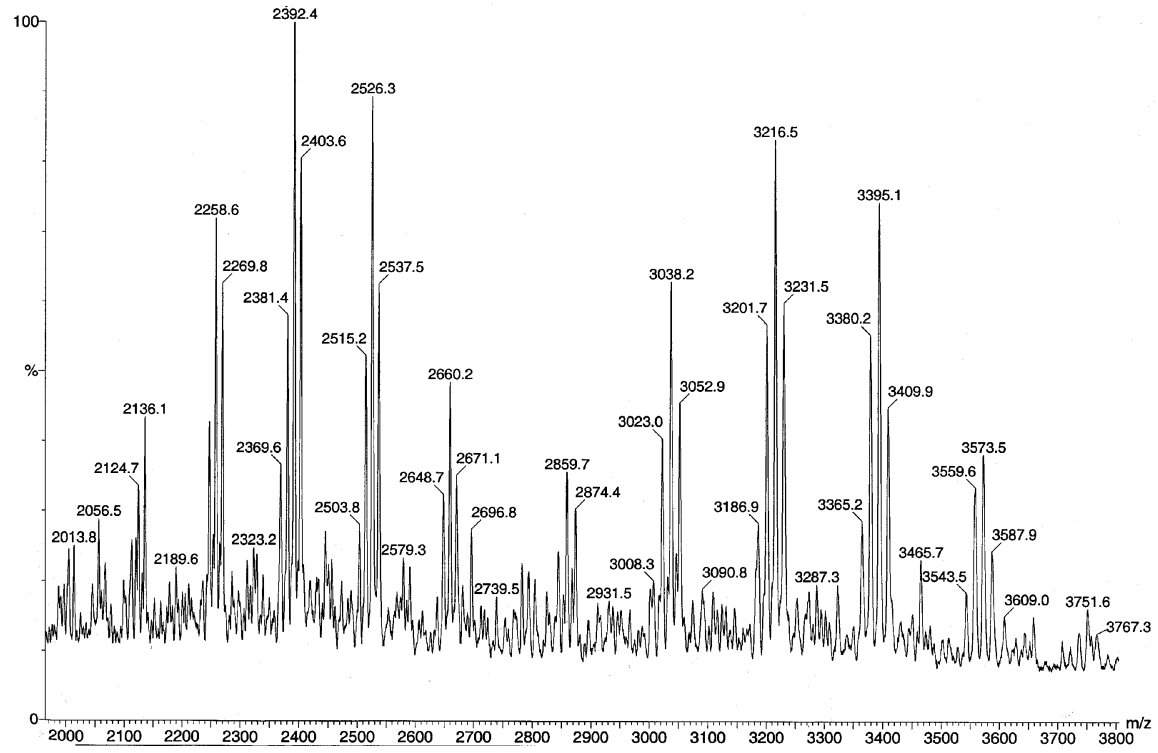

Figure 6. Mass spectrum (nano-ESI) of a metallodendritic assembly [2][5] $]_{8}$.

larger than those observed for metallodendritic assemblies based on $\mathrm{Pd}(\mathrm{II})$ complex $[5]^{-}$that bears a longer $\mathrm{C}_{6} \mathrm{SiMe}_{2}$ tether. For the third-generation metallodendritic assembly $[3][6]_{8}$ shifts to lower frequencies in the range of $0.18-0.34 \mathrm{ppm}$ were observed for the NCN moiety.

In the ${ }^{1} \mathrm{H}$ NMR spectra of metallodendritic assembly $[4][6]_{8}$ similar shifts were observed for the protons of the ammonium groups and tetraphenylsilane core unit (Figure $\mathrm{S} 1 \mathrm{a}-\mathrm{c}$ in the Supporting Information). Shifts to lower frequencies (0.23$0.34 \mathrm{ppm}$ ) were found for protons nearby ammonium sites in the core of the dendritic support $[4]^{8+}$, while shifts to higher frequencies of $0.04-0.22 \mathrm{ppm}$ were observed for the aryl protons of the tetraphenylsilane group in the core unit. The protons of the outer shell of the dodecyl groups showed no significant shifts. The resonances of $\mathrm{Pd}(\mathrm{II})$ complex $[6]^{-}$showed only minor shifts to lower frequencies $(0.02-0.09 \mathrm{ppm})$ in the presence of dendritic support $[4]^{8+}$. The most pronounced shifts were found for proton resonances of the $\mathrm{CH}_{2} \mathrm{Si}$ group of the tether unit.

A more detailed view of the 3D structures of these metallodendritic assemblies was obtained via NOE measurements. Given the relatively large molecular weight, both the NOESY and ROESY methodologies were employed. Sections of the NOESY spectra are shown in Figure 7. The numbering is shown in Chart 1.

For $[\mathbf{1}][\mathbf{5}]_{8}$, the protons $\mathrm{H} 1$, which are proximate to the sulfate anion, reveal contacts to the protons $\mathrm{H} 13-\mathrm{H} 15$ from the cation $[\mathbf{1}]^{8+}$ (see Figure 7 ), thereby clearly supporting the penetration of the anion through the shell to the cation. The protons in the next adjacent methylene group in the anion, $\mathrm{H} 2$, show a weaker cross-peak to the NMe resonance, $\mathrm{H} 14$, of the cation. A similar weak contact with $\mathrm{H} 14$ is observed for protons $\mathrm{H} 3-5$ from the hexamethylene chain. In the ROESY spectrum (Figure S2a in the Supporting Information), we find very weak cross-peaks from $\mathrm{H} 1$ of the anion to the inner aryl protons $\mathrm{H} 11,12$ of the cation; however, these are absent (presumably too weak) in the NOESY spectrum.

For $[2][5]_{8}$ a close inspection shows cross-peaks from the protons $\mathrm{H} 1$ of the anion to the protons $\mathrm{H} 13-\mathrm{H} 15$, near the positive charges of the dendritic cation (see Figure 7). We find
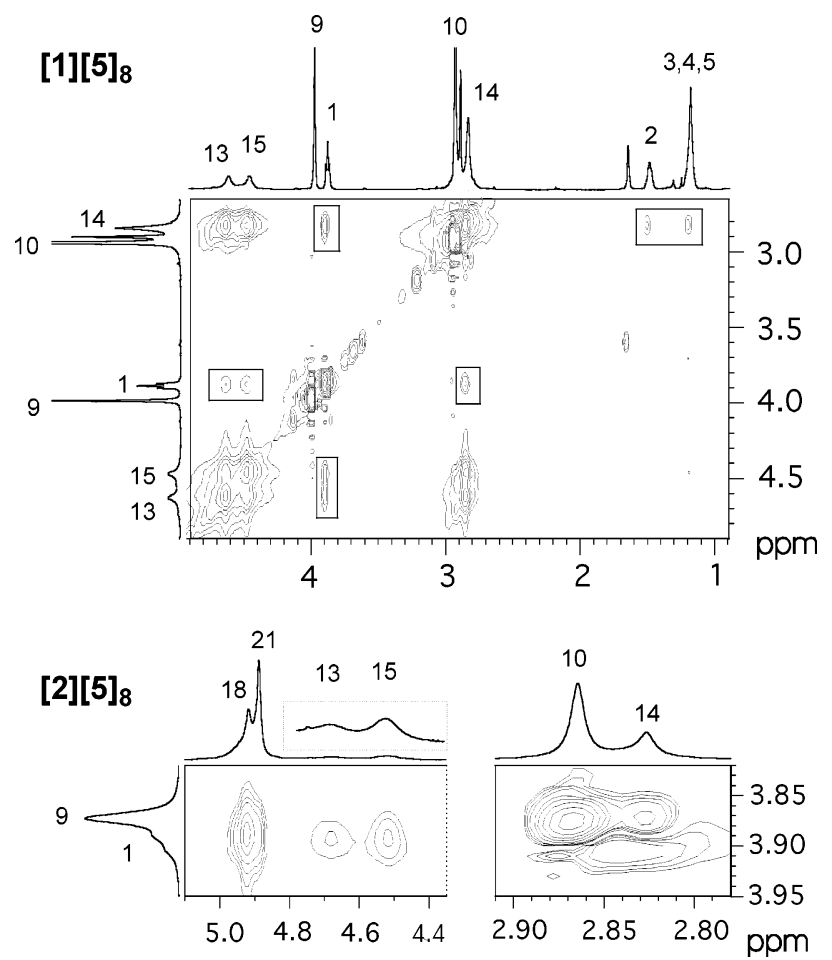

Figure 7. Sections of the NOESY spectra of $[\mathbf{1}][\mathbf{5}]_{8}$ and $[\mathbf{2}][\mathbf{5}]_{8}$. For $[\mathbf{1}][\mathbf{5}]_{8}$, the interionic cross-peaks are marked with rectangles. For $[2][5]_{8}$, the signals of the protons $\mathrm{H} 13$ and $\mathrm{H} 15$ are expanded.

interactions of $\mathrm{H} 2-5$ with a wide variety of protons, suggesting some spin diffusion; nevertheless, the cross-peaks from $\mathrm{H} 1$ are sufficiently unambiguous to allow us to conclude that in this case the anion, as well, reaches well into the depths of the dendritic cation.

The Overhauser results for $[\mathbf{3}][\mathbf{5}]_{8}$ are a bit more ambiguous, due to the increased signal overlap associated with the higher molecular weight (Figure S2b in the Supporting Information). We do not find contacts from $\mathrm{H} 1$ to the cationic protons $\mathrm{H} 14$, but we do observe clear cross-peaks from $\mathrm{H} 1-\mathrm{H} 5$ to $\mathrm{H} 15$ of the cation, suggesting that the anionic group does not penetrate quite as far in $[3][5]_{8}$ as in the previous assemblies. 
Chart 1. Numbering of Protons in $[1][5]_{8},[2][5]_{8}$, and [3][5 $]_{8}$ Used in the Overhauser and the Relaxation Time Experiments

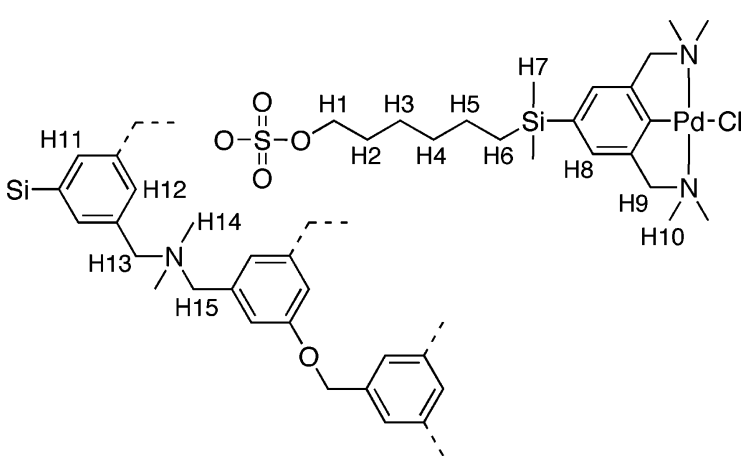

The metallodendritic assemblies $[\mathbf{1}][\mathbf{5}]_{8},[\mathbf{2}][\mathbf{5}]_{8}$, and $[\mathbf{3}][\mathbf{5}]_{8}$, as well as the corresponding unsupported $\mathrm{Pd}(\mathrm{II})$ complex, $\left[\mathrm{NBu}_{4}\right]$ [5], were studied by pulse gradient spin-echo (PGSE) NMR diffusion measurements in dichloromethane solution. For each species, the diffusion coefficients for the cation and anion were determined separately, and the results are shown in Table 2 and Figure 8.

In each of the dendritic assemblies, $[\mathbf{1}][\mathbf{5}]_{8},[\mathbf{2}][\mathbf{5}]_{8}$, and $\left.[3]_{8}\right]_{8}$, the $D$ values for the anion and cation within each assembly are identical within the experimental error, and thus one can conclude that these are strongly associated. Normally, transition metal salts in dichloromethane reveal only partial ion pairing in this solvent. ${ }^{19-21}$ Consequently, the observed association for $\left.[\mathbf{1}][\mathbf{5}]_{8},[\mathbf{2}]_{[5}\right]_{8}$, and $\left.[\mathbf{3}]_{[5}\right]_{8}$ in dichloromethane is most likely due to a combination of two factors: some ion pairing plus trapping of the Pd complex within the dendrimer structure. For $\left[\mathrm{NBu}_{4}\right][5]$, where there is no dendritic moiety, there is a significant difference in $D$ value between cation and anion, and the anion $[5]^{-}$diffuses much faster than in any of the dendritic assemblies.

Table 2 also shows the calculated hydrodynamic radii $\left(r_{\mathrm{H}}\right)^{22}$ determined from the $D$ values via the Stokes-Einstein equation. ${ }^{23,24}$ An increase in $r_{\mathrm{H}}$ of ca. $0.2 \mathrm{~nm}$ is observed on going from the first $\left([\mathbf{1}][\mathbf{5}]_{8}, r_{\mathrm{H}}=\right.$ ca. $\left.1.8 \mathrm{~nm}\right)$ to the second $\left([\mathbf{2}][\mathbf{5}]_{8}\right.$, $r_{\mathrm{H}}=$ ca. $\left.2.0 \mathrm{~nm}\right)$ as well as from the second to the third $\left([\mathbf{3}][5]_{8}\right.$, $r_{\mathrm{H}}=$ ca. $2.2 \mathrm{~nm}$ ) assembly generation.

Figure 8 shows that there is a small, but reproducible, difference in the $D$ values for cation and anion in $[1][5]_{8}$ (ca. $1.5 \%$ ) and $[2][5]_{8}$ (ca. 3.2\%), with the anion $[5]^{-}$diffusing slightly faster than the dendritic cations. This might be due to some equilibrium in which small quantities of the separated cations and anions contribute. In $[3][5]_{8}$, where the dendritic shell is larger, and [5] $]^{-}$is expected to be more tightly "trapped", this difference in $D$ values between cation and anion is not observed.

(19) Martinez-Viviente, E.; Rüegger, H.; Pregosin, P. S.; Lopez-Serrano, J Organometallics 2002, 21, 5841-5846.

(20) Pregosin, P. S.; Martinez-Viviente, E.; Kumar, P. G. A. Dalton Trans. 2003, 4007-4014.

(21) Martinez-Viviente, E.; Pregosin, P. S. Inorg. Chem. 2003, 42, 2209-2214.

(22) The hydrodynamic radius, $r_{\mathrm{H}}$, is an indication of the apparent size of the dynamic solvated particle. It represents the radius of a hypothetical hard sphere that diffuses with the same speed as the particle under examination.

(23) $D=(k T) /\left(6 \pi \eta r_{\mathrm{H}}\right)$ where $k$ is the Boltzman constant, $T$ the temperature, $\eta$ the viscosity of the solvent, and $r_{\mathrm{H}}$ the hydrodynamic radius of the diffusing particle. The viscosity at $300 \mathrm{~K}$ of $\mathrm{CH}_{2} \mathrm{Cl}_{2}$ was taken from Yaws, C. L. Chemical Properties Handbook; McGraw-Hill: New York, 1999; online: http//www.knovel.com.

(24) Edward, J. T. J. Chem. Educ. 1970, 47, 261-270.

(25) The copper measured by EDX spot analysis is due to the copper grid upon which the sample is deposited.

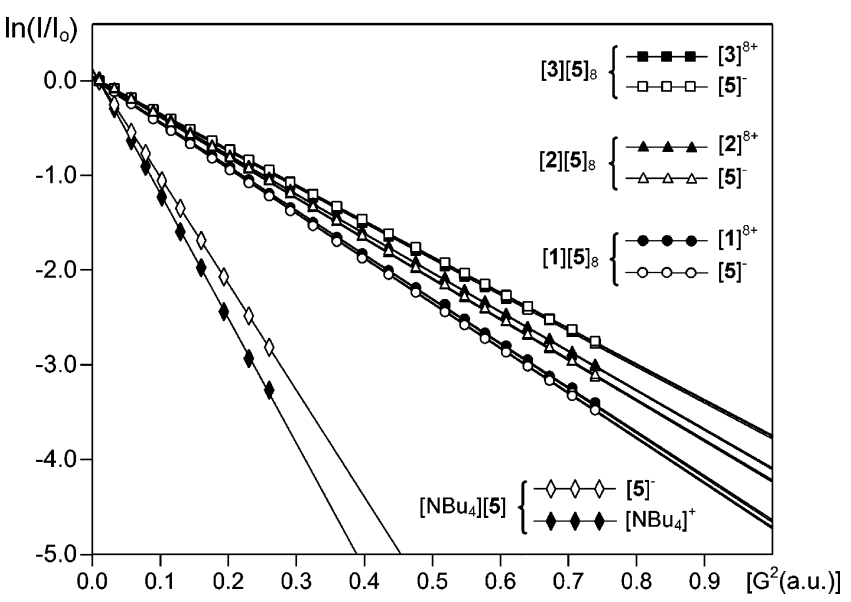

Figure 8. Plot of $\ln \left(I / I_{0}\right)$ vs arbitrary units proportional to the square of the gradient amplitude for ${ }^{1} \mathrm{H}$ PGSE diffusion measurements on $1 \times 10^{-3}$ $\mathbf{M}$ solutions of $\left.[\mathbf{1}]_{[\mathbf{5}}\right]_{8}$ (circles), $\left.[\mathbf{2}]_{[\mathbf{5}}\right]_{8}$ (triangles), $\left.[\mathbf{3}]_{[\mathbf{5}}\right]_{8}$ (squares), and $\left[\mathrm{NBu}_{4}\right][5]$ (diamonds) in $\mathrm{CD}_{2} \mathrm{Cl}_{2}$. The experimental points for the cations are represented with full symbols and those for the anion $[5]^{-}$with open symbols. Each of the lines in $[\mathbf{1}][\mathbf{5}]_{8},[\mathbf{2}][\mathbf{5}]_{8}$, and $[\mathbf{3}][\mathbf{5}]_{8}$ results from superposition of two $D$ determinations, using two different NMR signals of the fragment, except for the cation $[3]^{8+}$, where only one suitable NMR signal was available. The NMR parameters are the same for all the reproduced measurements $(\Delta=168 \mathrm{~ms}, \delta=2 \mathrm{~ms}, 32$ scans $)$.

Table 2. Diffusion Coefficients $(D)$ and Calculated Hydrodynamic Radii $\left(r_{\mathrm{H}}\right)$ for the Unsupported Pd(II) Complex, [NBu 4$][5]$, and the Corresponding Dendrimer-Supported Pd(II) Complexes of the First to Third Generation, $\left([1][5]_{8},[2][5]_{8} \text {, and }[3][5]_{8}\right)^{a}$

\begin{tabular}{lccccc}
\hline & \multicolumn{2}{c}{ anion $\left[\mathbf{5}^{-}\right.$} & & \multicolumn{2}{c}{ cation } \\
\cline { 2 - 3 } \cline { 5 - 6 } compound & $D^{b, c}$ & $r_{\mathrm{H}}(\mathrm{nm})$ & & $D^{b, c}$ & $r_{\mathrm{H}}(\mathrm{nm})$ \\
\hline$\left[\mathrm{NBu}_{4}\right][\mathbf{5}]$ & 7.19 & $0.74^{d}$ & & 8.42 & $0.63^{d}$ \\
{$[\mathbf{1}][\mathbf{5}]_{8}$} & 2.99 & $1.77^{e}$ & & 2.95 & $1.80^{e}$ \\
{$[\mathbf{2}][\mathbf{5}]_{8}$} & 2.70 & $1.96^{e}$ & & 2.62 & $2.02^{e}$ \\
{$[\mathbf{3}][\mathbf{5}]_{8}$} & 2.39 & $2.22^{e}$ & & 2.41 & $2.20^{e}$ \\
\hline
\end{tabular}

${ }^{a}$ All samples have been measured as $1 \times 10^{-3} \mathrm{M}$ solutions in $\mathrm{CD}_{2} \mathrm{Cl}_{2}$ at $300 \mathrm{~K} .{ }^{b}$ Units: $10^{-10} \mathrm{~m}^{2} \mathrm{~s}^{-1} \cdot{ }^{c}$ The values reported are the average of three different measurements, which differ by less than $3 \%$. The experimental error is ca. $\pm 2 \%$. ${ }^{d}$ Standard deviation is ca. $\pm 0.01 \mathrm{~nm} .{ }^{e}$ Standard deviation is ca. $\pm 0.03 \mathrm{~nm} . \eta\left(\mathrm{CH}_{2} \mathrm{Cl}_{2}, 300 \mathrm{~K}\right)=0.414 \times 10^{-3}$ $\mathrm{kg} \mathrm{s}^{-1} \mathrm{~m}^{-1}$.

The diffusion results in dichloromethane are in agreement with low values obtained in conductivity measurements (between 2 and $4.2 \mathrm{~S} \cdot \mathrm{cm}^{2} \cdot \mathrm{mol}^{-1}$ ) in the same solvent. These values are significantly lower than the result for $\left[\mathrm{NBu}_{4}\right][5], 11.8$ $\mathrm{S} \cdot \mathrm{cm}^{2} \cdot \mathrm{mol}^{-1}$, and fall well below the range that is characteristic for monoionic salts in dichloromethane $\left(19<k_{\mathrm{M}}<22\right.$ $\mathrm{S} \cdot \mathrm{cm}^{2} \cdot \mathrm{mol}^{-1}$ ), indicating substantial immobilization of $[5]^{-}$ within the dendritic support.

We have also studied the diffusion behavior of the dichloromethane solvent in each of the solutions and compared it with the $D$ value obtained from the pure solvent. The data are shown in Table S1. For the larger dendrimers there seems to be a slight decrease in the $D$ value of the solvent. This effect might arise from the contribution of occluded solvent molecules.

Electron Microscopic Analysis of Metallodendritic Assembly. Transmission electron microscopy (TEM) images were obtained of metallodendritic assembly $[2][5]_{8}$ by dipping a polymer-coated copper grid in a dilute solution of $[2][5]_{8}$ in wet acetone. The sample was blotted to remove excess of sample solution and subjected to TEM analysis. The presence of the palladium complexes in the assemblies renders them directly visible without additional staining. The TEM micrograph shows 
a)
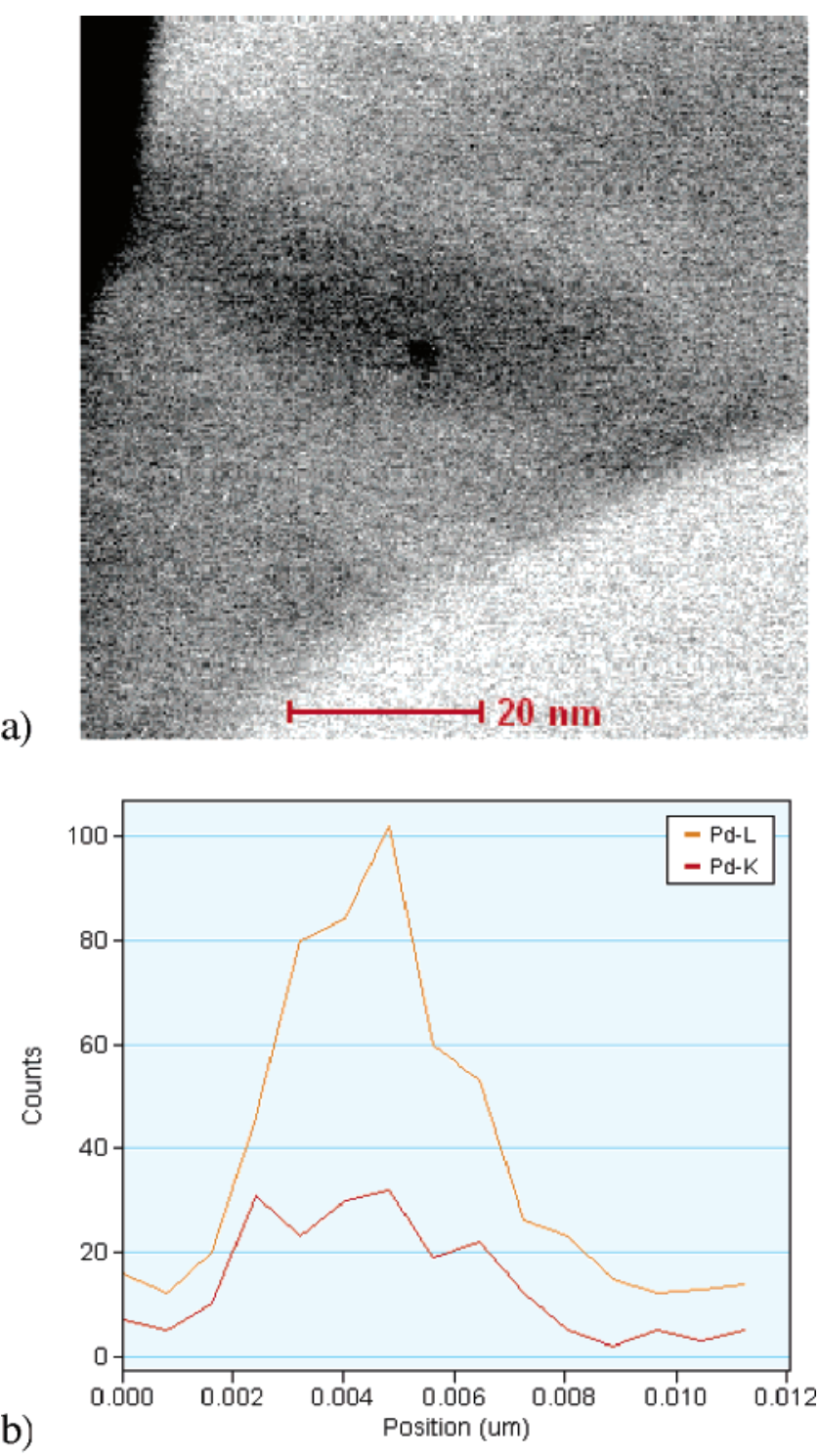

b)

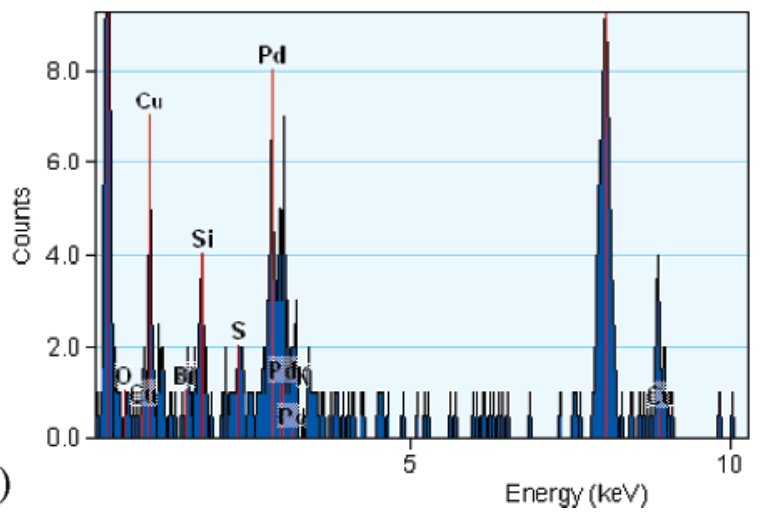

Figure 9. (a) TEM micrograph of metallodendritic assembly [2][5]8. (b) EDX line scan; palladium concentration observed by EDAX line scan across the spot. (c) EDX scan at the center of the spot (ref 25).

metallodendritic assembly [2][5 $]_{8}$ in the solid state as a circular spot with a diameter of $4 \mathrm{~nm}$ (Figure 9). This diameter is similar to the size dimensions determined by PGSE analysis (Table 2) and calculated by molecular modeling (vide infra).

To analyze the elemental composition of the spot, an energydispersive analysis of X-rays (EDAXS or EDX) was performed
(Figure 9, parts b and c). The EDX spot analysis showed that besides palladium various other characteristic elements such as sulfur and silicon were present at the spot, which typically resembles the elemental composition of metallodendritic assembly [2][5] $]_{8}$ (Figure 9c). An EDX line scan across the spot showed that elements that are characteristic for $[2][5]_{8}$, such as palladium, silicon, and sulfur, are only present at the spot (Figure 9b).

Molecular Modeling. Molecular mechanics calculations (MMFF94) ${ }^{26}$ were carried out to obtain an impression of both the location of the Pd(II) sites and the size of the assemblies. The optimized molecular structures of the metallodendritic assemblies consist of a rather spherical dendritic backbone of the host in which the anionic tails of the Pd(II) complexes are buried close to the cationic sites in the dendrimer core (Figure 10). In case of the first-generation dendrimers ([1] [5 $]_{8}$ and $\left.[1][6]_{8}\right)$, the palladium headgroups are exposed near the periphery of the dendritic backbone. Even when the soft condensed shell of these dendrimers is fully "stretched", the anionic tail of the guest is large enough to bridge the distance between the cationic core and the periphery, thereby keeping the palladium headgroups exposed. Upon increasing the dendrimer generation, the Pd(II) sites become more embedded by the dendritic host. This is most pronounced for third-generation dendrimer $[\mathbf{3}][\mathbf{6}]_{8}$, in which the Pd(II) sites are embedded by the dendritic shell. These findings strongly support the earlier results obtained by NMR spectroscopy.

The dimensions of the metallodendritic assemblies clearly increase going from the first-generation dendrimer, for $[\mathbf{1}][\mathbf{5}]_{8}$ $4.2 \times 4.5 \times 3.4 \mathrm{~nm}^{3}$, to the third-generation dendrimer, for $[3][5]_{8} 5.0 \times 5.4 \times 4.5 \mathrm{~nm}^{3}$. These calculated dimensions are comparable to the dimensions derived from the PGSE NMR experiments and from TEM analysis. Interestingly, the size dimensions of the first- and second-generation metallodendritic assemblies are determined by the length of the $\mathrm{Pd}(\mathrm{II})$ guest molecules, whereas the size of the third-generation assembly is set by the dendritic backbone. The shape of the assemblies becomes more spherical at higher dendrimer generations.

The calculated structure of metallodendritic assembly [4][6] $]_{8}$ clearly shows an "open structure" compared to the other metallodendritic assemblies with a polybenzyl aryl shell. The $\operatorname{Pd}(\mathrm{II})$ sites are located between the dodecyl groups of the outer shell of the dendritic support. The dodecyl groups were set to a stretched, pseudolinear conformation prior to the optimization of the molecular structure. Although the pseudolinear conformation of the dodecyl groups is retained during the optimization, the aliphatic tails can easily adopt various alternative conformations at room temperature. The molecular structure of $[\mathbf{4}][\mathbf{6}]_{8}$ depicted in Figure 10b should, therefore, be considered as a "fully stretched" structure of this assembly.

Application in Homogeneous Catalysis. The metallodendritic assemblies were tested on their catalytic performance in the aldol condensation reaction between benzaldehyde and methyl isocyanoacetate in dichloromethane (reaction 1 and Figure 11). ${ }^{17}$ The catalytic performances were monitored at regular time intervals by $\mathrm{GC}$ analysis and compared to those of the unsupported $\mathrm{Pd}(\mathrm{II})$ complexes $\left[\mathrm{NBu}_{4}\right][5]$ and $\left[\mathrm{NBu}_{4}\right][\mathbf{6}]$ (Table 3).

In the first hour, metallodendritic assemblies $[\mathbf{1}][\mathbf{5}]_{8},[\mathbf{2}][\mathbf{5}]_{8}$, and $[\mathbf{3}][\mathbf{5}]_{8}$ showed slightly higher turnover frequencies (TOF

(26) SPARTAN SGI, version 5.1.1; Wavefunction Inc.: Irvine, CA. 


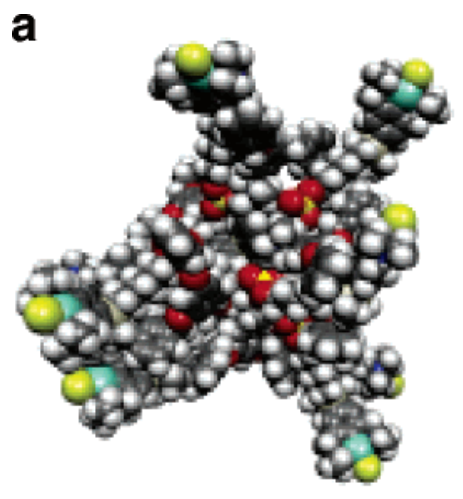

$[1][5]_{8}$

$4.2 \times 4.5 \times 3.4 \mathrm{~nm}^{3}$
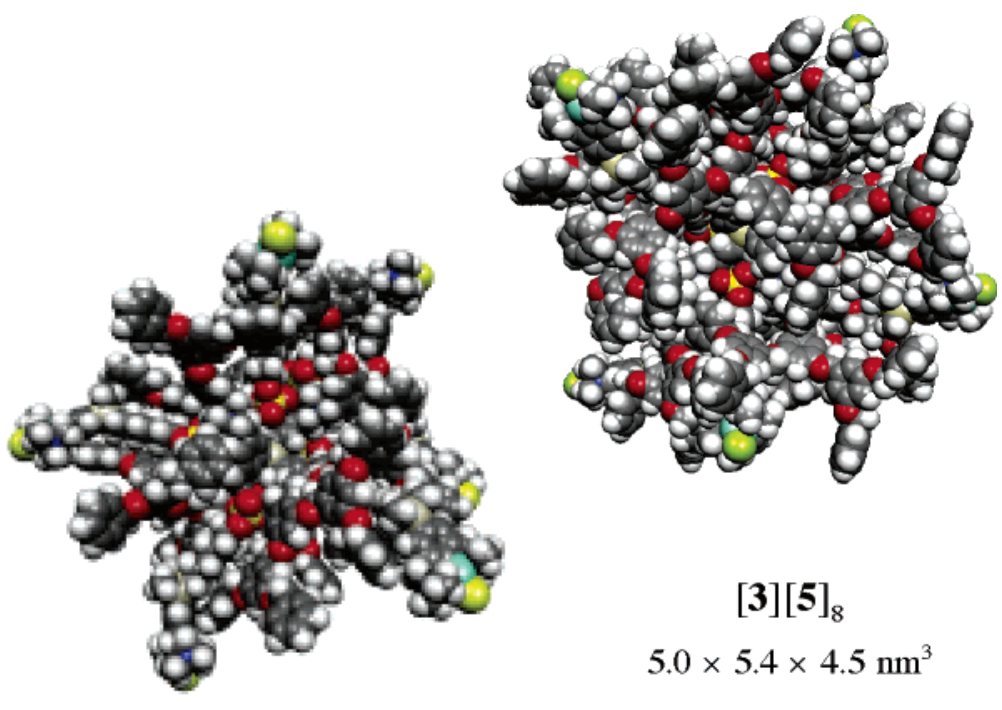

$[3][5]_{8}$

$[2][5]_{8}$

$5.0 \times 4.2 \times 4.5 \mathrm{~nm}^{3}$

b

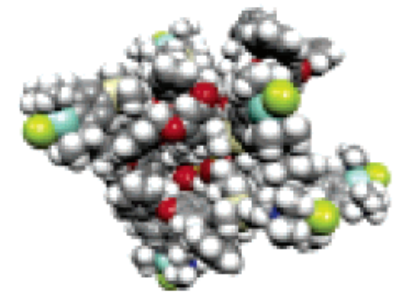

$[\mathbf{1}][6]_{8}$

$4.0 \times 4.2 \times 2.8 \mathrm{~nm}^{3}$

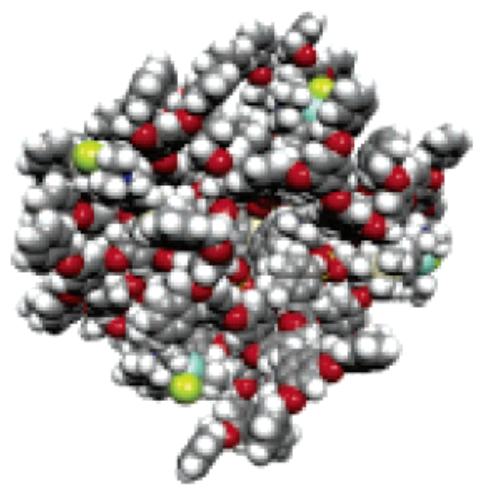

$[3][6]_{8}$

$4.5 \times 5.0 \times 4.7 \mathrm{~nm}^{3}$

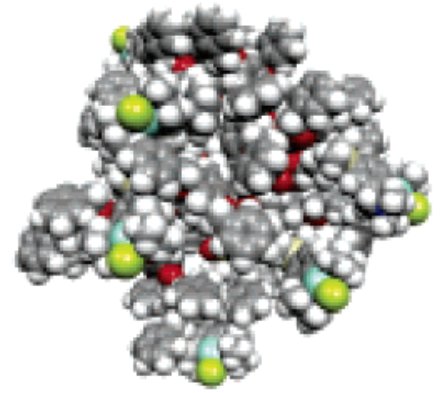

[2][6] $]_{8}$

$4.2 \times 4.1 \times 3.9 \mathrm{~nm}^{3}$

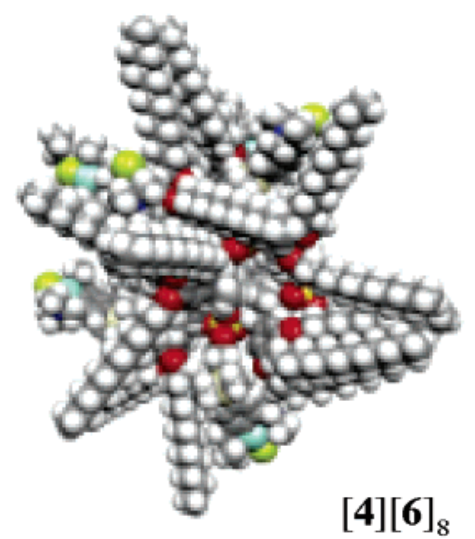

$5.0 \times 4.7 \times 4.5 \mathrm{~nm}^{3}$

Figure 10. (a) Molecular modeling structures of metallodendritic assemblies $[\mathbf{1}][\mathbf{5}]_{8},[\mathbf{2}][\mathbf{5}]_{8}$, and $[\mathbf{3}][\mathbf{5}]_{8}$. (b) Molecular modeling structure of dendrimer assemblies $[\mathbf{1}][\mathbf{6}]_{8},[\mathbf{2}][\mathbf{6}]_{8},[\mathbf{3}][\mathbf{6}]_{8}$, and $[\mathbf{4}][\mathbf{6}]_{8}$.

of 17,17 , and 13 , respectively) than the unsupported $\mathrm{Pd}(\mathrm{II})$ complex (TOF of $\left[\mathrm{NBu}_{4}\right][5]$ : 12) (Figure 11, top). After $3 \mathrm{~h}$, however, the metallodendritic assemblies showed lower conversions than the unsupported Pd(II) complex. Metallodendritic assemblies $\left.[\mathbf{1}][\mathbf{5}]_{8},[\mathbf{2}]_{[\mathbf{5}}\right]_{8}$, and $\left.[\mathbf{3}]_{[\mathbf{5}}\right]_{8}$ all gave conversions of approximately $83 \%$ after $24 \mathrm{~h}$, whereas the unsupported $\mathrm{Pd}(\mathrm{II})$ complex displayed $95 \%$ conversion.
The metallodendritic assemblies $[\mathbf{1}][\mathbf{6}]_{8},[\mathbf{2}][\mathbf{6}]_{8},[\mathbf{3}][\mathbf{6}]_{8}$, and $[4][6]_{8}$, which bear Pd(II) complex [6] ${ }^{-}$with a shorter $\mathrm{C}_{3} \mathrm{SiMe}_{2}$ tether, showed similar initial TOFs as metallodendritic assemblies $[\mathbf{1}][\mathbf{5}]_{8},[\mathbf{2}][\mathbf{5}]_{8}$, and $[\mathbf{3}][\mathbf{5}]_{8}$ (Figure 11, bottom). After $5 \mathrm{~h}$, however, significantly lower conversions (39\%) were observed for the second- and third-generation dendritic assemblies $[2][6]_{8}$ and $[3][6]_{8}$, respectively, with respect to those 

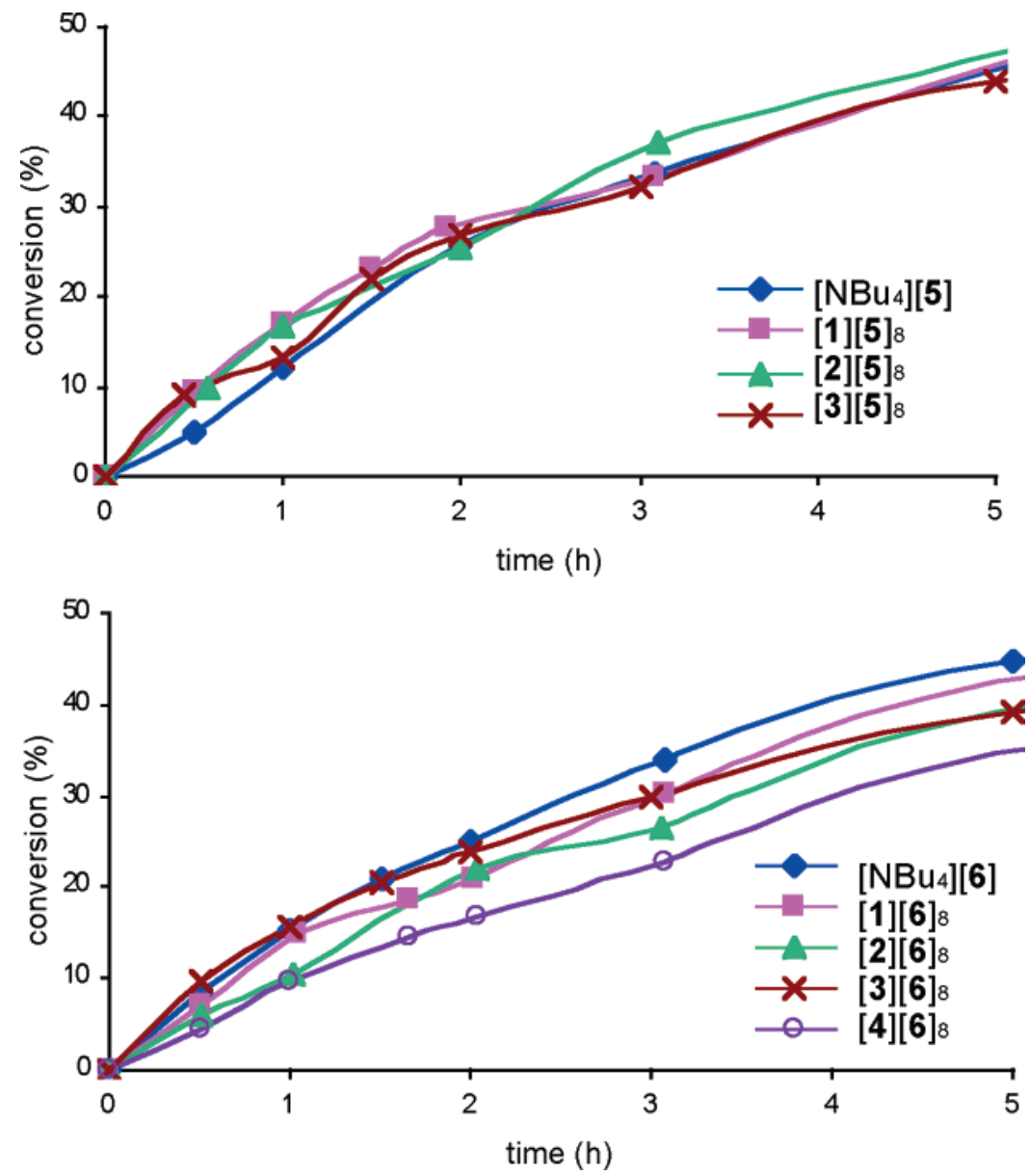

Figure 11. Catalytic performance of metallodendritic assemblies $[\mathbf{1}][\mathbf{5}]_{8},[\mathbf{2}][\mathbf{5}]_{8},[\mathbf{3}][\mathbf{5}]_{8}$, and unsupported $\mathrm{NCN}-\mathrm{Pd}(\mathrm{II})$ complex $[\mathrm{NBu} 4][\mathbf{5}]$ (top) and $[\mathbf{1}][\mathbf{6}]_{8}$, $[2][6]_{8},[3][6]_{8},[\mathbf{4}][6]_{8}$, and unsupported $\mathrm{NCN}-\mathrm{Pd}(\mathrm{II})$ complex $\left[\mathrm{NBu}_{4}\right][\mathbf{6}]$ (bottom) in the aldol condensation reaction between benzaldehyde and methyl isocyanoacetate monitored in time.

Table 3. Catalytic Performance of the Dendrimer-Supported and Unsupported Pd(II) Complexes as Lewis Acidic Catalysts in the Aldol Condensation Reaction between Methyl Isocyanoacetate and Benzaldehyde in $\mathrm{CH}_{2} \mathrm{Cl}_{2}{ }^{a}$

\begin{tabular}{lccc}
\hline \multicolumn{1}{c}{ catalyst } & TOF $^{b}$ & $\begin{array}{c}\text { conversion } \\
(\%)^{c}\end{array}$ & $\begin{array}{c}\text { trans } \\
(\%)^{d}\end{array}$ \\
\hline$\left[\mathrm{NBu}_{4}\right][\mathbf{5}]$ & 12 & 95 & 72 \\
{$[\mathbf{1}][\mathbf{5}]_{8}$} & 17 & 82 & 69 \\
{$[\mathbf{2}][\mathbf{5}]_{8}$} & 17 & 83 & 67 \\
{$[\mathbf{3}][\mathbf{5}]_{8}$} & 13 & 83 & 70 \\
{$\left[\mathrm{NBu}_{4}\right][\mathbf{6}]$} & 15 & 83 & 74 \\
{$[\mathbf{1}][\mathbf{6}]_{8}$} & 15 & 71 & 72 \\
{$[\mathbf{2}][\mathbf{6}]_{8}$} & 11 & 73 & 72 \\
{$[\mathbf{3}][\mathbf{6}]_{8}$} & 16 & 70 & 71 \\
{$[\mathbf{4}][6]_{8}$} & 10 & 69 & 73 \\
\hline
\end{tabular}

${ }^{a}$ Reaction carried out in $\mathrm{CH}_{2} \mathrm{Cl}_{2}(5 \mathrm{~mL})$ at room temperature in the presence of $10 \mathrm{~mol} \%$ of $(i-\mathrm{Pr})_{2} \mathrm{EtN}$ and $1 \mathrm{~mol} \%$ of catalyst in terms of [Pd]. ${ }^{b}$ Per hour per [Pd] during the first hour. ${ }^{c}$ Calculated after $24 \mathrm{~h}$ by GC analysis using dodecane as an internal standard. ${ }^{d}$ Calculated after $24 \mathrm{~h}$.

of $[2][5]_{8}$ and $[3][5]_{8}$. The lowest conversion after $5 \mathrm{~h}(34 \%)$ was recorded for assembly $[4][6]_{8}$, which bears apolar dodecyl groups at the periphery. After $24 \mathrm{~h}$, metallodendritic assemblies $[\mathbf{1}][\mathbf{6}]_{8},[\mathbf{2}][\mathbf{6}]_{8},[\mathbf{3}][\mathbf{6}]_{8}$, and $[\mathbf{4}][\mathbf{6}]_{8}$ displayed similar conversions in the range of $69-73 \%$.

The stereoselectivity, in terms of cis and trans oxazoline products, remained fairly constant going from unsupported $\mathrm{Pd}(\mathrm{II})$ complexes $\left[\mathrm{NBu}_{4}\right][5]$ and $\left[\mathrm{NBu}_{4}\right][\mathbf{6}]$ to the dendrimersupported $\mathrm{Pd}(\mathrm{II})$ complexes. The dendrimer-supported and unsupported $\mathrm{Pd}(\mathrm{II})$ complexes all afforded ca. $70 \%$ trans oxazoline products.

\section{Discussion}

Synthesis of the Metallodendritic Assemblies. We have demonstrated a novel approach for the noncovalent attachment of homogeneous catalysts to a dendritic support. Arylpalladium complexes $[\mathbf{5}]^{-}$and $[\mathbf{6}]^{-}$were attached to octacationic coreshell dendrimers of the first, second, and third generation, i.e., dendritic entities $[\mathbf{1}]^{8+},[\mathbf{2}]^{8+}$, and $[\mathbf{3}]^{8+}$, respectively, via straightforward anion exchange reactions under mild conditions to afford discrete metallodendritic assemblies in all cases (Figure 5). In a similar manner arylpalladium complex [6] ${ }^{-}$was noncovalently attached to octacationic dendrimer $[4]^{8+}$, which bears an apolar outer shell of dodecyl groups. The number of permanent ammonium sites in the core of the dendrimers determines the maximum number of arylpalladium complexes that can be bound to these dendritic supports. The number of $\mathrm{Pd}(\mathrm{II})$ complexes is independent of the steric bulk or the nature of the dendritic shell as is demonstrated by the higher generation assemblies, suggesting a relatively "open" structure for these dendrimer generations.

Structural Aspects and Binding Properties of the Metallodendritic Assemblies. The diagnostic peak shifts in ${ }^{1} \mathrm{H}$ NMR of the proton peaks nearby the ammonium sites in the core of the dendritic supports combined with the Overhauser data strongly indicate that the sulfato groupings of the $\mathrm{Pd}(\mathrm{II})$ 
complexes in the dendritic assemblies are located nearby the ammonium sites in the core of the dendritic support as is depicted in Scheme 1. The Pd(II) site of [5] $]^{-}$is "exposed" at the periphery of the dendritic structure of $[\mathbf{1}]^{8+}$. To encapsulate the $\mathrm{Pd}(\mathrm{II})$ sites of metallodendritic assembly $[\mathbf{1}][\mathbf{5}]_{8}$ two strategies can be followed. In strategy I (Figure 4), the generation of the dendritic support was increased, which leads to a thicker dendritic shell that can enclose the Pd(II) complex. An alternative approach (strategy 2) to encapsulate the $\mathrm{Pd}(\mathrm{II})$ sites is to use $\mathrm{NCN}-\mathrm{Pd}(\mathrm{II})$ complex [6] ${ }^{-}$which bears a shorter $\left(\mathrm{C}_{3} \mathrm{SiMe}_{2}\right)$ tether than $[\mathbf{5}]^{-}$.

The NCN moiety was used as a probe in NMR spectroscopy to study the location of the palladium sites with respect to the dendritic backbone. Upon increasing the size of the dendrimer and/or reducing the length of the tether, the peaks of the protons of the NCN moiety shift to lower frequencies (Figure S1, parts $\mathrm{b}$ and $\mathrm{c}$ ), which suggests that the palladium sites become more embedded in the dendrimer structure of the higher generations. The increased electron density around the protons of the NCN moiety is most likely caused by the electron-rich aryl rings (anisotropic effects) and the oxygen atoms of the dendritic shell of the dendritic support. The strongest shifts to lower frequencies were observed for the NCN moiety of $\left.[3]_{[6}\right]_{8}$ (Figure S1c). The fact that no shifts were observed for the NCN moiety in $[4][6]_{8}$ means either that the $\mathrm{Pd}(\mathrm{II})$ complex is located outside the dendritic structure or that the electronic field created by the aliphatic shell is too small to affect the electron density around the NCN-Pd(II) sites. It seems likely to assume that the polybenzyl aryl dendrons create more electronic density around the NCN moiety than the apolar alkyl groups of $[4][6]_{8}$.

This structural picture is further supported by the molecular structures calculated by molecular mechanics (Figure 10), which show that the palladium sites are exposed at the exterior of the first-generation dendritic backbone but are embedded by the third-generation dendritic backbone. Furthermore, the increase of $T_{1}$ NMR relaxation times of the periphery of these assemblies indicates that the dendritic shell becomes denser and adopts a solid-phase behavior for the higher generations in solution (Figures S2-S6 in the Supporting Information). Further evidence for the embedded palladium sites was provided by the solubility profiles of the metallodendritic assemblies. The solubility profiles of the higher generation assemblies resemble those of their corresponding dendrimers with bromide anions, which illustrates that the $\mathrm{Pd}(\mathrm{II})$ complexes become more embedded in the dendritic support. In addition, $[4][6]_{8}$, which bears an outer shell of apolar dodecyl groups, is soluble in organic solvents as apolar as hexane.

PGSE NMR spectroscopy and conductivity measurements revealed that the octacationic dendrimers and the arylpalladium complexes are strongly associated in dichloromethane solution. PGSE NMR spectroscopy and TEM analysis, furthermore, revealed that the metallodendritic assemblies have nanoscopic size dimensions in solution as well as in the solid state. Their unimolecular structure and nanoscopic dimensions allow for isolation of the assemblies from reaction mixtures, as was demonstrated by means of purification of these assemblies via membrane dialysis. In some cases the acceptor phases of the dialysis experiments also contained some metallodendritic assemblies. No clear correlation was found between the generation of the assembly and the retention by the membrane, which is due to the fact that during these dialysis experiments various solvents were used. The type of solvent can strongly affect the properties of organic membranes ${ }^{2 b, 27}$ and, as a result, the outcome of a dialysis experiment. Nevertheless, these dialysis experiments demonstrate that these metallodendritic assemblies are compatible with membrane filtration techniques.

Halide Scrambling. The halide scrambling observed in the ESI-MS spectra of assemblies $[\mathbf{1}][\mathbf{5}]_{8},[\mathbf{2}][\mathbf{5}]_{8},[\mathbf{1}][\mathbf{6}]_{8},[\mathbf{2}][\mathbf{6}]_{8}$, and $[4][6]_{8}$ was not observed in their elemental analysis data due to the large molecular masses. Since halide scrambling was also observed in the NMR spectra of the metallodendritic assemblies, it is likely that halide scrambling occurs during the synthesis of the assemblies. The ratios between $\mathrm{NCN}-\mathrm{Pd}-\mathrm{Cl}$ and $\mathrm{NCN}-\mathrm{Pd}-\mathrm{Br}$ complexes determined with mass spectrometry correlate with the ratios found in ${ }^{13} \mathrm{C}\left\{{ }^{1} \mathrm{H}\right\}$ NMR spectra of the assemblies and vary between 4:4 and 2:6. Most of the metallodendritic assemblies bear more bromide than chloride anions, which seems to indicate a preference of the $\mathrm{NCN}-\mathrm{Pd}$ complex for bromide anions. Halides can have a significant influence on the steric and electronic properties of organometallic complexes and may also have a pronounced effect on transition metal catalyzed reactions. ${ }^{28}$ A recent study of our group revealed that the halide $(\mathrm{X})$ has no significant effect on the catalytic performance of $\mathrm{NCN}-\mathrm{Pd}-\mathrm{X}$ complexes $(\mathrm{X}=\mathrm{Cl}$, $\mathrm{Br}$ ) in the aldol condensation of benzaldehyde and methyl isocyanoacetate. ${ }^{11}$ For the present study this allows a fair comparison of the catalysis by the noncovalent dendritic assemblies. To avoid halide scrambling in the assemblies, starting materials with a single type of halide may be used in their synthesis.

Application in Homogeneous Catalysis. Through the investigation of a series of noncovalent metallodendritic assemblies of different dendrimer generations and containing organometallic moieties with different tether lengths (see Figure 4), a subtle interplay between the relative sizes of the assembly constituents and their catalytic performance was found.

The initial TOF during the first hour of the metallodendritic assemblies and unsupported $\mathrm{Pd}(\mathrm{II})$ complexes $\left[\mathrm{NBu}_{4}\right][5]$ and $\left[\mathrm{NBu}_{4}\right][6]$ are comparable. Throughout the catalytic run, similar conversions were observed for metallodendritic assemblies that bear Pd(II) complexes [5] ${ }^{-}$or [6] $]^{-}$. Only for assemblies [2][6 $]_{8}$ and $[\mathbf{3}][\mathbf{6}]_{8}$ were significantly lower conversions found compared to the first generation $\left([\mathbf{1}][\mathbf{6}]_{8}\right)$ and unsupported $\mathrm{Pd}(\mathrm{II})$ complex. The minor decrease in catalytic activity during the first hours may be due to a lower accessibility of the dendrimer-embedded catalytic sites of the macromolecular supported catalysts compared to that of unsupported Pd(II) complex $\left[\mathrm{NBu}_{4}\right][6]$. The nature of the dendritic shell slightly influences the catalytic properties of the metallodendritic assembly as is demonstrated by assembly $[4][6]_{8}$, which bears an apolar shell of dodecyl groups. During the first hours of catalysis, the catalytic activity of this assembly is significantly lower than those of the assemblies with a polybenzyl aryl ether shell, while the selectivity remains constant.

The minor effect of the size and nature of the dendritic supports on the catalytic activity and product selectivity of their assemblies indicates that their molecular structures are relatively

(27) Scarpello, J. T.; Nair, D.; Freitas dos Santos, L. M.; White, L. S.; Livingston, A. G. J. Membr. Sci. 2002, 203, 71-85.

(28) For a review on halide effects in transition metal catalyzed reactions see, for example: Fagnou, K.; Lautens, M. Angew. Chem. 2002, 41, 26-47. 
"open", which keeps the catalytic Pd(II) sites reasonably well exposed resulting in comparable degrees of access of reactants. Extension and densification of the dendritic shell, however, e.g., by increasing the dendrimer generation or introducing more branching points, could lead to more effective encapsulation of the catalytic sites. This strategy may also result in a more pronounced nano environment around the $\mathrm{Pd}(\mathrm{II})$ sites that influences the catalytic performance. Whether the extension and densification of the dendritic shell would also affect the binding properties in the core remains to be investigated. The fact that the size and nature of the reported dendritic backbone do not strongly influence the performance of the supported catalyst can be used to advantage when higher generation dendrimers are required to ensure effective catalyst recovery by means of nanofiltration. An additional advantage of catalytic sites embedded in the dendrimer structure could be the protection of these sites against deleterious side reactions, e.g., within a continuous flow reactor, by the steric bulk of the surrounding dendritic "arms", which would improve the lifetime of the catalyst. The nature of the dendritic shell can furthermore be used to tune the solubility profile of the supported catalyst to the desired reaction media.

This study represents a "proof-of-principle" study on the noncovalent immobilization of homogeneous catalysts. The use of a soluble molecular support (a dendrimer) in this study enabled a detailed insight in the constitution of the immobilized catalyst in terms of the formation of well-defined structures and the relative fixation and orientation of the homogeneous catalyst with respect to the support. In addition, this molecular approach allowed the notion that, depending on the flexibility of the support, catalyst encapsulation or enfolding within a supporting material does not have to result in altered catalytic performances. These findings may have implications for the use of hyperbranched polymers and polymeric resins as catalyst supporting materials through related noncovalent approaches, which could be of interest from a more commercial or practical point of view.

\section{Conclusion}

We have described a novel approach for the noncovalent attachment of a well-defined number of homogeneous catalysts to dendritic supports, i.e., via a (straightforward) ion-exchange reaction at room temperature, which results in the formation of discrete metallodendritic assemblies of nanoscopic size. The location of the $\mathrm{Pd}(\mathrm{II})$ sites, which are attached through a "tether" unit to the core of the dendritic support, can be tuned either by varying the thickness of the dendritic shell of the ionic support or by altering the length of the tether unit of the homogeneous catalysts. Upon encapsulation of the $\mathrm{Pd}(\mathrm{II})$ sites, only minor decreases in catalytic activity were observed, while the product selectivity remained constant up to the third dendrimer generation. Extension and densification of the dendritic shell, e.g., by increasing the dendrimer generation or introducing more branching points, could lead to more effective encapsulation of the catalytic sites, which may influence the catalytic properties of the assembly to advantage. Efforts toward the dendritic incorporation of other homogeneous catalysts using the present noncovalent strategy are currently being undertaken in our laboratories, as are investigations on such dendritic assemblies in sequential catalytic transformations.

Acknowledgment. The National Research School Combination Catalysis (NRSC-C) (R.J.M.K.G) and Utrecht University (R.vdC.) are acknowledged for financial support. P.S.P. thanks the Swiss National Science Foundation and the ETH Zürich for financial support. E.M.-V. thanks the Seneca Foundation (Comunidad Autónomona de la Región de Murcia, Spain) for a grant. The authors thank Cees Versluis and Anca C.H.T.M. van der Kerk-van Hoof (Bijvoet Institute, Biomolecular Mass Spectrometry, Utrecht University) for ESI-MS analyses.

Supporting Information Available: Full experimental details on the synthesis and characterization of reported compounds; information on diagnostic assembly induced NMR chemical shifts (Figure S1a-c); NOESY and ROESY spectra (Figure S2a,b); solvent (dichloromethane) diffusion coefficients (Table $\mathrm{S} 1)$. This material is available free of charge via the Internet at http://pubs.acs.org.

JA060079T 